\title{
Long noncoding RNA Saf and splicing factor 45 increase soluble Fas and resistance to apoptosis
}

\author{
Olga Villamizar ${ }^{1,3, *}$, Christopher B. Chambers ${ }^{1, *}{ }^{*}$, Janice M. Riberdy ${ }^{2}$, Derek A. Persons ${ }^{2}$ \\ and Andrew Wilber ${ }^{1}$ \\ ${ }^{1}$ Department of Medical Microbiology, Immunology and Cell Biology, Southern Illinois University School of Medicine, \\ Springfield, Illinois, USA \\ 2 Department of Hematology, St. Jude Children's Research Hospital, Memphis, Tennessee, USA \\ ${ }^{3}$ Department of Microbiology, Pontificia Universidad Javeriana, Bogotá, Colombia \\ * These authors have contributed equally to this work \\ Correspondence to: Andrew Wilber, email: awilber@siumed.edu
}

Keywords: alternative splicing, apoptosis, Fas, long-noncoding RNA, Saf

Received: November 03, $2015 \quad$ Accepted: January 29,2016 Published: February 11, 2016

\section{ABSTRACT}

In multicellular organisms, cell growth and differentiation is controlled in part by programmed cell death or apoptosis. One major apoptotic pathway is triggered by Fas receptor (Fas)-Fas ligand (FasL) interaction. Neoplastic cells are frequently resistant to Fas-mediated apoptosis, evade Fas signals through down regulation of Fas and produce soluble Fas proteins that bind FasL thereby blocking apoptosis. Soluble Fas (sFas) is an alternative splice product of Fas pre-mRNA, commonly created by exclusion of transmembrane spanning sequences encoded within exon 6 (Fas $\triangle E x 6$ ). Long non-coding RNAs (IncRNAs) interact with other RNAs, DNA, and proteins to regulate gene expression. One IncRNA, Fas-antisense or Saf, was shown to participate in alternative splicing of Fas pre-mRNA through unknown mechanisms. We show that Saf is localized in the nucleus where it interacts with Fas receptor pre-mRNA and human splicing factor 45 (SPF45) to facilitate alternative splicing and exclusion of exon 6. The product is a soluble Fas protein that protects cells against FasL-induced apoptosis. Collectively, these studies reveal a novel mechanism to modulate this critical cell death program by an IncRNA and its protein partner.

\section{INTRODUCTION}

Programmed cell death or apoptosis results from an active cellular response designed to eliminate unnecessary cells and maintain tissue homeostasis. This process is initiated by a variety of stimuli including activation of specific cellular receptors including Fas/Apo-1/CD95, a member of the tumor necrosis factor (TNF) receptor superfamily. Cells expressing Fas undergo apoptosis when treated with agonistic antibodies $[1,2]$ or upon interaction with Fas ligand (FasL) [3]. Through these receptor/ ligand interactions, Fas plays a critical role in cellular proliferation, differentiation, and survival. This delicate balance is affected when soluble forms of this and related surface receptors are produced by alternative splicing of pre-mRNA, a known function of long non-coding RNAs (lncRNAs).

LncRNAs are transcripts longer than 200 nucleotides that have no protein coding potential, but function in an expanding array of cellular processes during normal development and in disease [4-8]. LncRNAs have a relatively low level of evolutionary conservation even within mammalian species [5, 8, 9]. They are generally transcribed at lower levels compared to protein coding genes and can be polyadenylated or not. LncRNAs are found in the nuclear or cytoplasmic compartments and interact with other RNAs, DNA, and proteins either through Watson-Crick base pairing or secondary, stem-loop structures created by RNA folding [8]. These characteristics allow lncRNAs to perform a variety of cellular functions, including to regulate gene expression through transcriptional and post-transcriptional mechanisms $[4,8]$.

One class of lncRNAs is natural antisense transcripts (NATs). NATs are transcribed from the opposite strand of a protein coding gene and may or may not overlap with 
portions of coding sequences [10]. It is estimated that approximately two-thirds of human transcripts have at least partial antisense counterparts [11]. Many of these transcripts do not encode proteins, and the majority is expressed at lower levels than the corresponding sense RNA [10, 12-14]. Antisense lncRNAs can control nearly every level of gene regulation through a variety of mechanisms operating in cis or trans [15]. In cis, NATs can interact with the sense transcript or genes within the same region, whereas in trans, the interaction is with genes located at distant loci or even other chromosomes [16, 17]. NATs can interact with sense RNA to form RNA duplexes by virtue of their ability to base pair. Consequently, lncRNAs can act as highly specific sensors of pre-mRNA or mRNA, with this interaction resulting in different posttranscriptional outcomes, all of which modulate sense mRNA expression. Through these interactions, lncRNAs have been reported to influence pre-mRNA splicing [18], RNA transport or nuclear retention, or mRNA stability [reviewed in 19].

Alternative splicing regulation by lncRNAs has been shown to occur through chromatin modification [18] and by modulating the levels and subcellular distribution of alternative splicing effector proteins [20]. Fas premRNA can be alternatively spliced to produce sFas, which inhibits Fas-mediated apoptosis [21]. A NAT lncRNA (Fas-AS1 or Saf) transcribed in reverse orientation and from the opposite strand of intron 1 of Fas genomic sequences was shown to modulate Fas pre-mRNA alternative splicing by exclusion of exon 6 , which encodes for the Fas transmembrane domain [22]. Saf was found to be expressed at varying levels in different human tissues and in human cancer cell lines and Saf over-expression in Jurkat $\mathrm{T}$ cells provided protection from Fas-mediated apoptosis [22]. However, the mechanism by which Saf lncRNA mediates Fas pre-mRNA alternative splicing is unknown.

Here, we provide evidence that Saf interacts with Fas pre-mRNA through complementary base pairing and also interacts with human splicing factor 45 (SPF45) in human cancer cell lines. The interaction of Fas premRNA, Saf, and SPF45 results in skipping of Fas exon 6 , increased production of sFas protein, and protection from Fas-mediated cell death. Our results demonstrate that direct interaction between a lncRNA and a splicing factor are sufficient to modulate alternative splicing of a target pre-mRNA. Altogether, these results reveal a novel mechanism to regulate this critical cell death program by an IncRNA and its protein partner.

\section{RESULTS}

\section{Saf is localized to the nucleus but has limited effects on genome wide transcription}

Because many lncRNAs are highly compartmentalized [23], we analyzed Saf expression in cytosolic and nuclear fractions of HeLa cells (Figure 1A) and verified fraction purity by western blot (Figure 1B). RT-PCR showed Saf was highly enriched in the nucleus relative to $47 \mathrm{~S}$ pre-ribosomal RNA and U87 small nucleolar RNA (snoRNA) controls (Figure 1C), representing $97 \%$ of total Saf transcripts quantified by real time PCR (Figure 1D). The effect of Saf on genome wide transcription was assessed by transducing Jurkat $T$ cells and K562 cells with lentiviral particles encoding for Saf lncRNA and GFP using independent promoters (see Materials and Methods) or GFP alone (control) (Figure $2 \mathrm{~A}$, top) and enriching transduced populations based on expression of GFP by fluorescence-activated cell sorting (FACS) (Figure 2A, bottom). Microarray studies confirmed Saf over-expression in both cell types that was coincident with a 2 -fold change in a limited number of probe sets: Jurkat $\mathrm{T}$ cells (41 probes; $0.08 \%$, Figure $2 \mathrm{~B}$ ) and K562 cells (21 probes; $0.04 \%$, Supplementary Figure S1). Comparison of genes with altered expression levels revealed that none were conserved between the two cell types or located on the same chromosome as Saf.

\section{Saf regulates Fas receptor exon 6 splicing and production of soluble Fas}

Yan et al. [22] demonstrated that Saf influenced alternative splicing of Fas receptor pre-mRNA to produce a number of shorter transcripts. We tested the ability of Saf to modulate Fas pre-mRNA splicing by engineering HeLa cells to express Saf/GFP or GFP by lentiviral transduction. Cells transduced with Saf/ GFP were separated into populations with low or high Saf expression by FACS based on intensity of GFP fluorescence. Alternative splicing of Fas pre-mRNA was monitored by RT-PCR using primers designed to exons 5 and 7 of Fas (Supplementary Table S1B). Saf overexpression significantly enriched for Fas mRNA lacking exon 6 (Fas $\Delta \mathrm{Ex} 6$ ), which encodes for a soluble Fas (sFas) protein, compared with GFP control cells (Figure 2C and 2D). ELISA of conditioned supernatants from GFP and Saf transduced cells for sFas protein confirmed that increasing Saf expression generates increasing amounts of sFas protein (Figure 2E; GFP: $88 \pm 3$; Saf Lo: 116 \pm 6 ; Saf Hi: $139 \pm 2 \mathrm{pg} / \mathrm{mL} / 10^{6}$ cells). Thus, enforced expression of Saf enhances Fas pre-mRNA splicing. Further characterization of the functional effect of Saf on Fas exon 6 alternative splicing was tested by silencing 
A

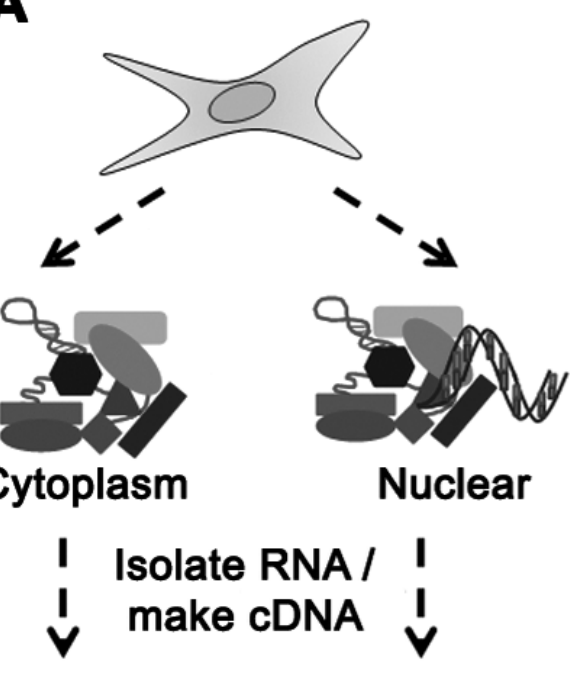

RT-PCR; qRT-PCR

C

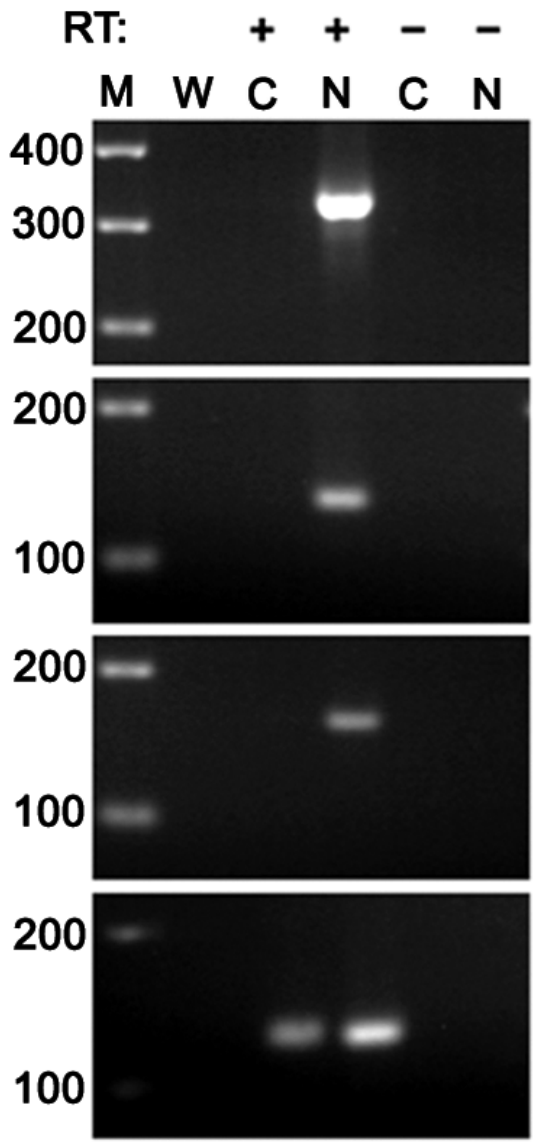

B

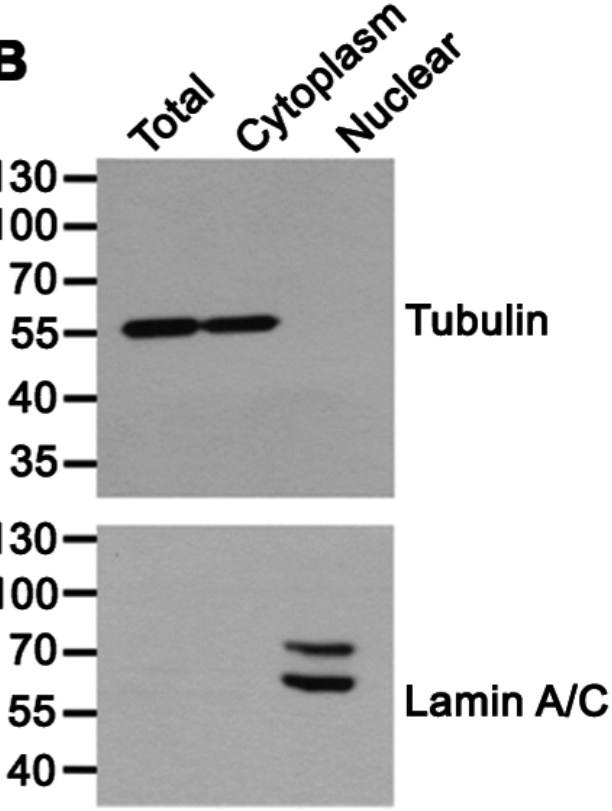

D

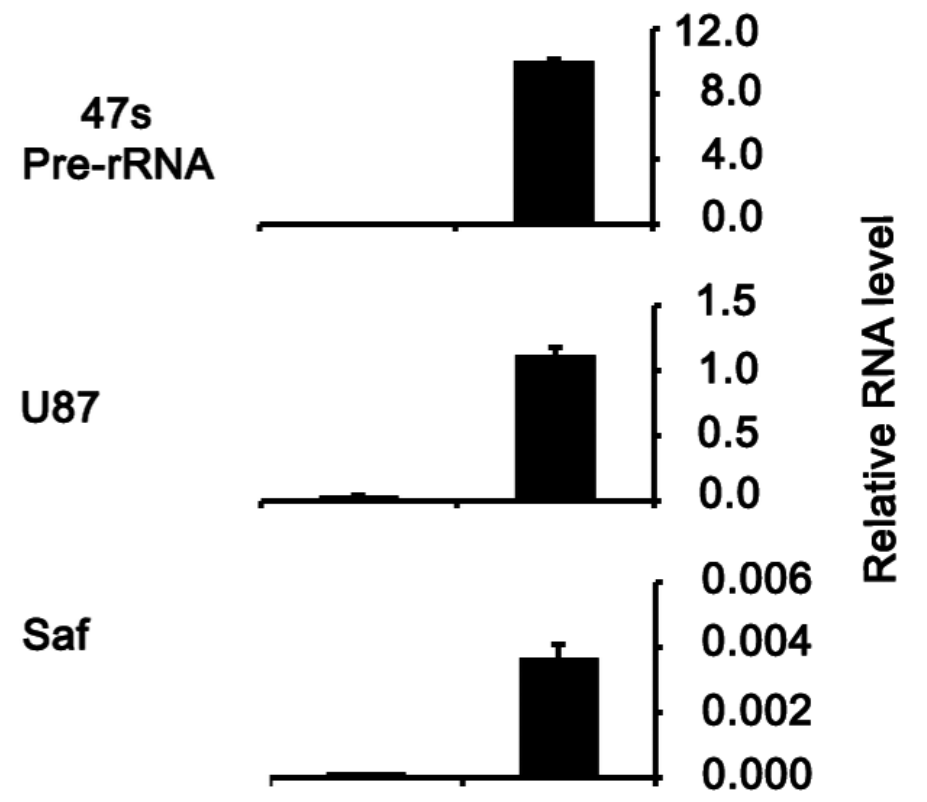

Cytoplasm Nuclear

\section{RPL13A}

Figure 1: Saf is localized to the nucleus. A. Schematic diagram showing separation of cells into cytoplasmic and nuclear fractions, RNA isolation, cDNA synthesis, and PCR analyses. B. Western immunoblot of total cell and subcellular lysates using antibodies to Tubulin or Lamin A/C to demonstrate fraction purity. Molecular weights (kDal) are indicated. C. RT-PCR of 47S pre-rRNA, U87 snoRNA, Saf lncRNA, and RPL13A mRNA for cytoplasm (C) and nuclear (N) fractions with (+) and without (-) reverse transcription (RT). M, 100-bp ladder; W, no template. D. Real time quantitative RT-PCR analysis of transcripts detected in indicated fractions relative to RPL13A plotted as mean $\pm \mathrm{SD}$ of three independent experiments. 
endogenous Saf in HeLa cells using small interfering RNA (siRNA) sequences. Saf specific siRNAs decreased mean Saf levels by $38 \%$ (Figure $2 \mathrm{~F}$ and $2 \mathrm{G}$ ) relative to non-targeting siRNAs, resulting in a $20 \%$ decrease in sFas protein in conditioned supernatants as measured by ELISA (Figure 2H). Collectively, these results demonstrate that Saf regulates Fas exon 6 alternative splicing to increase the production of sFas.

\section{Saf interaction with Fas pre-mRNA is specific and enriched at splice junction sequences}

LncRNAs can interact with other RNAs through complementary base pairing $[8,10]$. Several NATs use this mechanism to regulate splicing of overlapping sense transcripts [24]. Saf is encoded within intronic sequences located between exons 1 and 2 of Fas and does not overlap coding sequences. To determine the relative specificity of Saf interaction with Fas RNA, HeLa cell nuclear extracts were treated with proteinase $\mathrm{K}$ and resulting cellular
RNA mixed with biotin-labeled, in vitro transcribed Saf or firefly luciferase (control) RNA (Supplementary Figure S2A). RNA-RNA complexes recovered with magnetic streptavidin beads were converted to cDNA and RT-PCR performed using primers specific for constitutive exons of Fas, four genes with known splice variants (GCIP, HMG2L1, ARHGEF1, and CDK7), and two genes that do not have documented splice products (U87 and RPL13A) (Supplementary Figure S2B). These RNA pull-down experiments revealed that only Saf lncRNA-Fas RNA hybrids were recovered, suggesting the formation of a specific double-stranded RNA intermediate.

To explore this possibility, RNA pull-down experiments were repeated using biotin-labeled Saf RNA and recovered RNA samples were divided such that one sample was treated with RNAse A before preparing cDNA, while the other sample was used to directly prepare cDNA. Semi-quantitative RT-PCR was performed using primers specific to Fas exon:intron sequences (Figure 3A and Supplementary Table S1C). Amplified products were quantified by densitometry analysis and calculated as
A

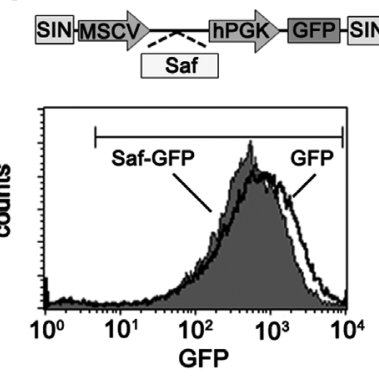

$\mathbf{E}$

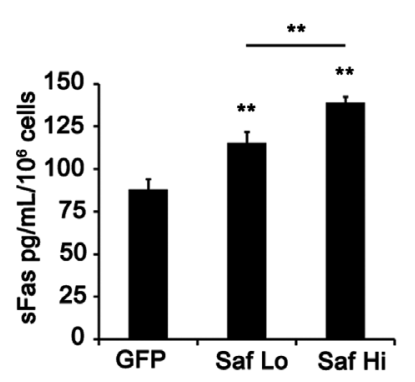

B

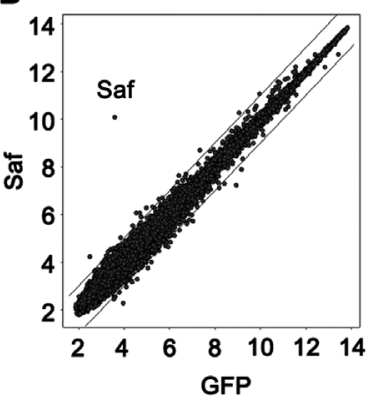

$\mathbf{F}$

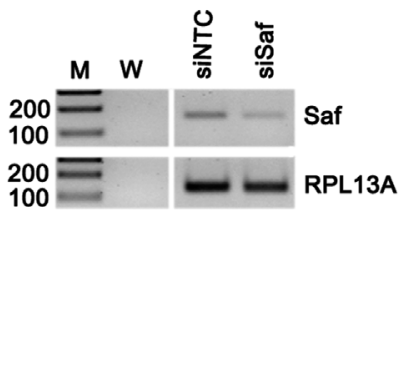

C

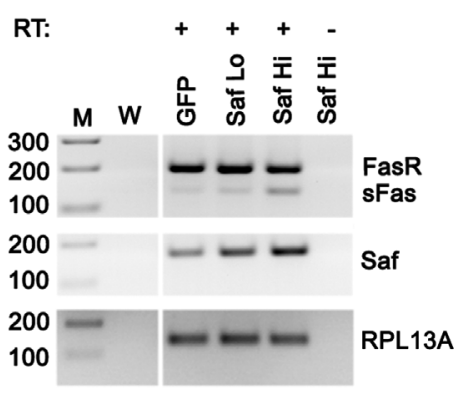

G

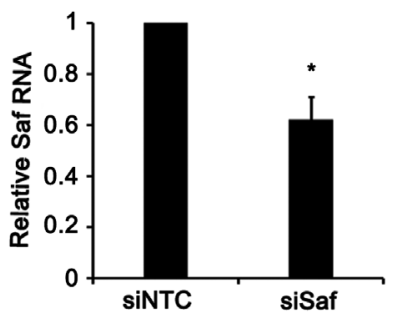

D

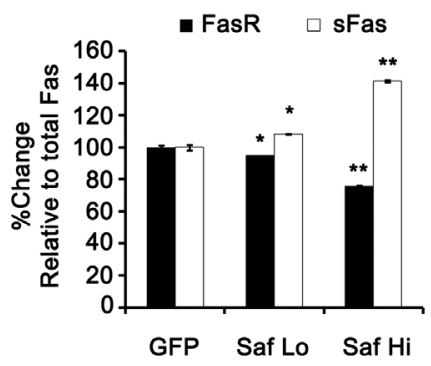

H

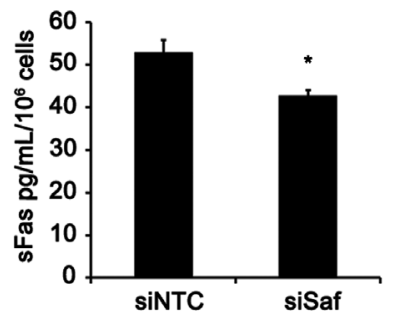

Figure 2: Saf overexpression enhances production of the soluble form of Fas receptor mRNA and protein. A. Top, diagram of lentiviral vectors encoding GFP or Saf/GFP. Bottom, flow cytometry histogram of GFP expression for transduced cell populations. B. $\log _{2}$ normalized intensity of probes plot for microarrays performed on Jurkat T cells. Linear regressions highlight \pm 2 -fold change where Saf is labeled. C. HeLa cells with stable expression of GFP or Saf/GFP were isolated of total RNA and subjected to PCR with (+) and without (-) RT using primers to Saf, exons 5 and 7 of Fas, and the internal control RPL13A. D. Densitometry analysis of mRNA products for Fas that include (FasR) or lack (sFas) exon 6 sequences normalized to RPL13A and plotted as percent change relative to total Fas for three independent experiments (GFP control set to 100). E. Conditioned supernatants from HeLa cells expressing GFP or Saf/GFP were assayed for soluble Fas (sFas) by ELISA. F. siRNA knockdown of Saf in naïve HeLa cells determined by end point RT-PCR and G. real time quantitative RT-PCR with normalization to RPL13A (siNTC; set to 1). (H) Conditioned supernatants from these cultures assayed for sFas by ELISA. All quantitative results are plotted as mean \pm SD for at least three independent experiments. M, 100-bp ladder; W, no template; NTC, non-targeting control; RT, reverse transcriptase. * indicates $p<0.05$ (Student's $t$-test); ** indicates $p \leq 0.001$ (one-way ANOVA with Newman-Keuls post-hoc test). Vertical white lines have been inserted to represent repositioned lanes on the gel images. 


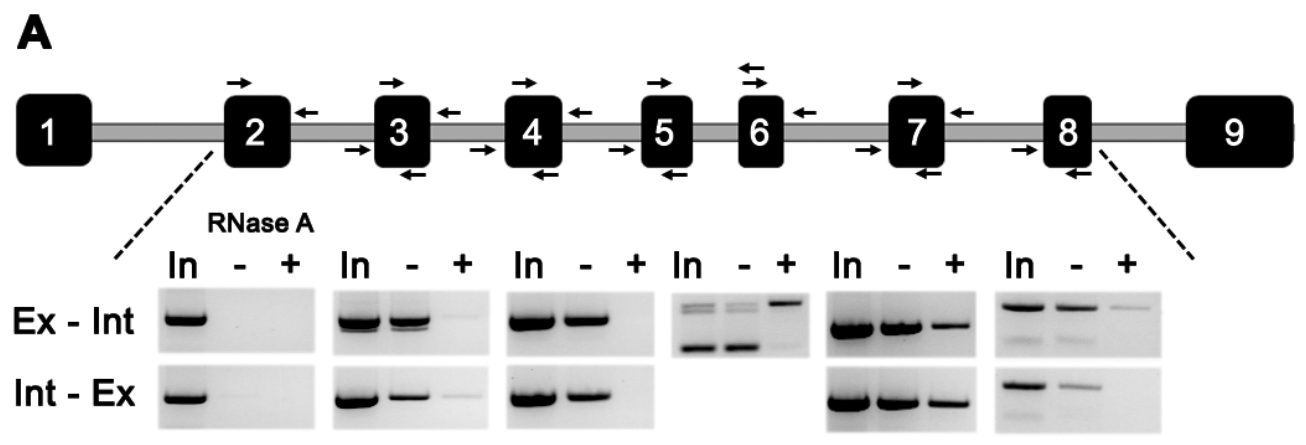

Ex 2-3 Ex 3-4 Ex 4-5 Ex 5-6 Ex 6-7 Ex 7-8

B
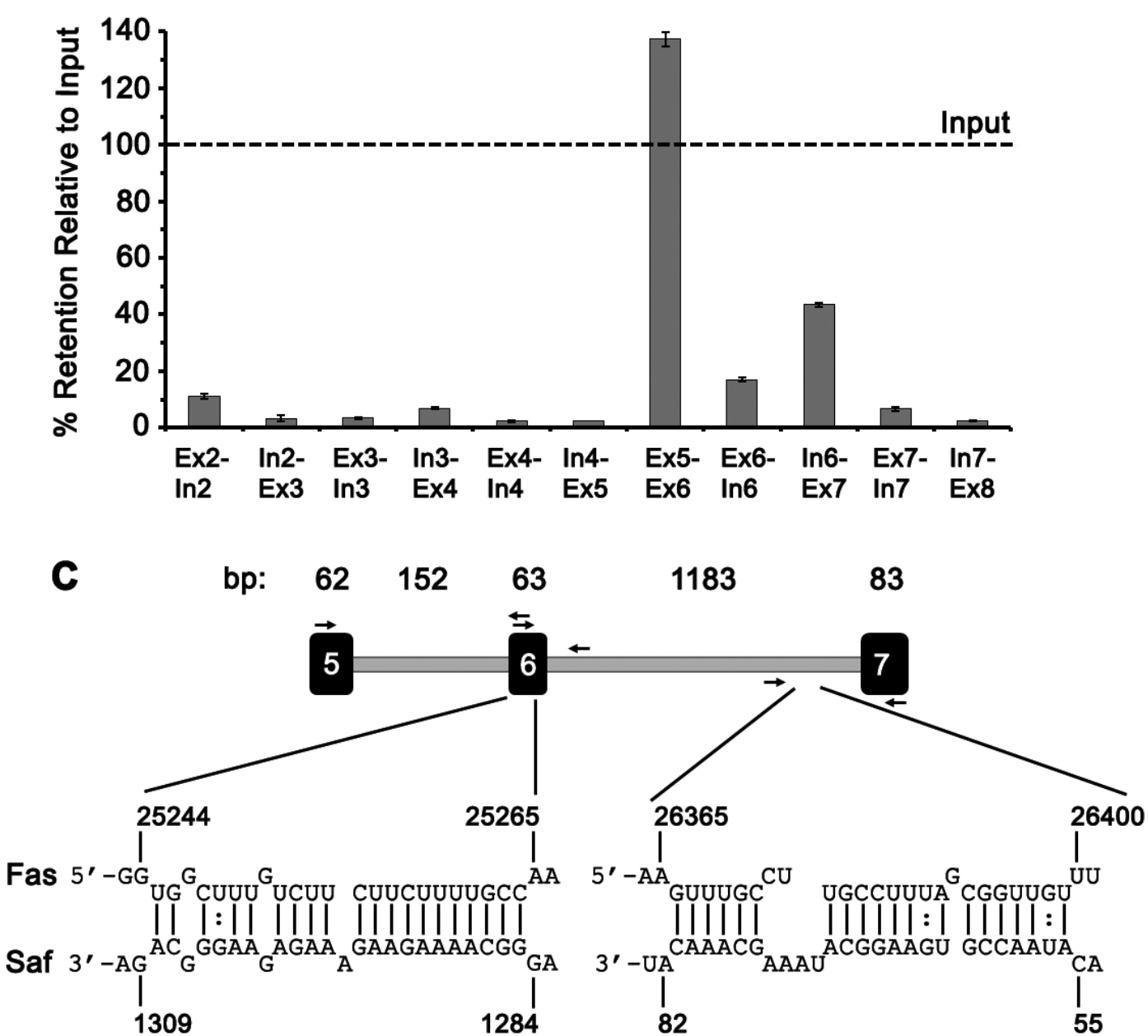

\section{Free Energy: $\quad-14.2$ (kcal/mol)}

$-16.1$

Figure 3: Saf interacts with Fas pre-mRNA at a commonly spliced region. A. Top, Diagram of Fas pre-mRNA showing the nine coding exons (filled rectangles) and intervening introns (grey lines) where variations in length are used to demonstrate relative size. Arrows indicate the relative position and direction of primers. Bottom, inverse agarose gel images of RT-PCR products generated using primer combinations that amplify exon (Ex) to intron (Int) or Int to Ex sequences for RNA used as input (In) in RNA pulldown experiments or subsequently recovered and left untreated (-) or RNase-A treated (+). B. Densitometry analysis of Fas pre-mRNA products for each of the indicated primer pairs reported as percent retained relative to input. Data are plotted as mean \pm SD of three independent RNA pulldown experiments. C. Top, Enlarged diagram of exons 5 to 7 of Fas pre-mRNA with size (base pairs, bp) of each exon and intron indicated and primers depicted by arrows. Bottom, sequence information for the predicted interaction sites between Fas and Saf and calculated free energy values. 
percent of input. This RNAse A protection assay revealed the strongest interaction between Saf lncRNA and Fas pre-mRNA occurred at exon 5-6 and exon 6-7 junctions with mean recoveries of $137 \%$ and $44 \%$ relative to input, respectively; recovery was limited $(<15 \%)$ for all other regions examined (Figure $3 \mathrm{~B}$ ). To identify potential regions of Saf that interacted with sequences encoded from exon 5 to exon 7 of Fas pre-mRNA we used IntaRNA to predict target sites $[25,26]$. This analysis indentified two regions with favorable interaction kinetics (Figure $3 \mathrm{C}$ ): the first in exon $6(-14.2 \mathrm{kcal} / \mathrm{mol})$ and second in the intron between exons 6 and $7(-16.1 \mathrm{kcal} / \mathrm{mol})$. Together, these RNA interaction studies demonstrate a specific association between Saf and Fas pre-mRNA that includes regions within or surrounding the alternatively spliced exon 6 .

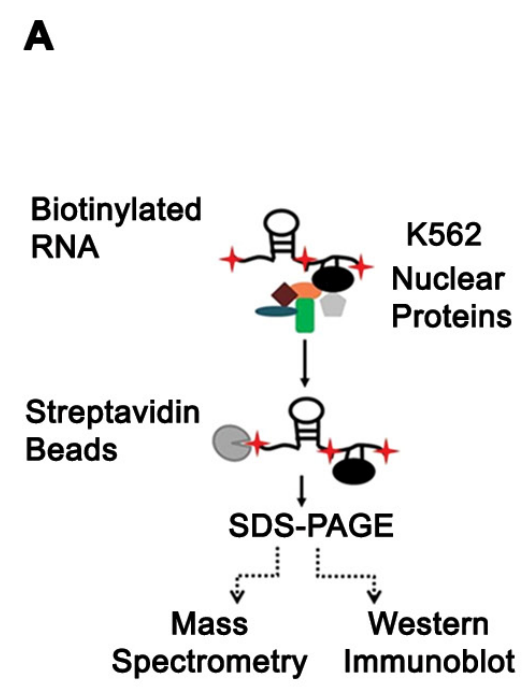

C

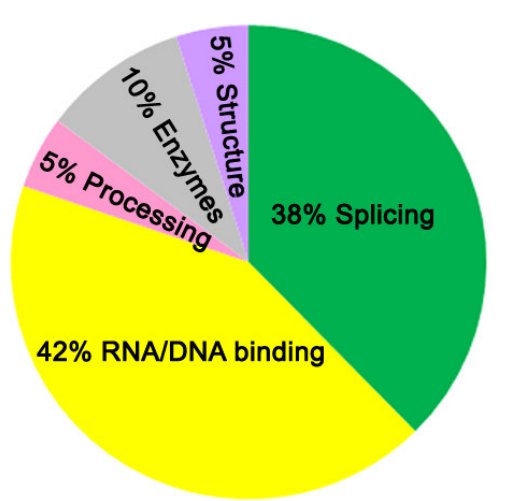

Saf interacts with human splicing factor 45 (SPF45)

Alternative splicing of pre-mRNA occurs in the nucleus as a function of the spliceosome [27, 28]. To identify nuclear binding partners for Saf, we incubated biotin labeled Saf RNA produced in anti-sense or sense orientations with nuclear protein extracts (Figure 4A). Nuclear lysates and proteins bound to RNA were separated by SDS-PAGE and visualized with silver stain (Figure 4B) or subjected to mass spectrometry for identification. Twenty-one proteins (Supplementary Table S2) were identified from several functional classes (Figure 4C). One of these, human splicing factor 45 (SPF45, also known as RNA-binding motif 17), was reported to have a role in pre-

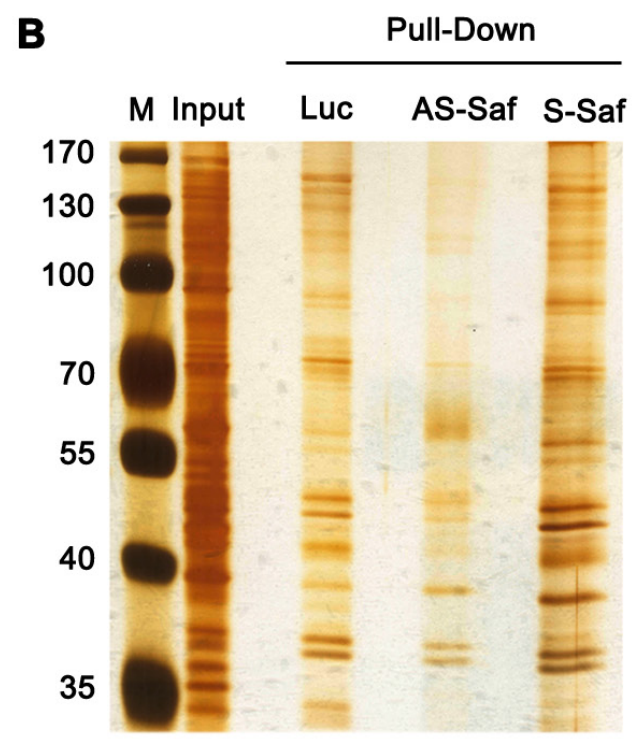

D

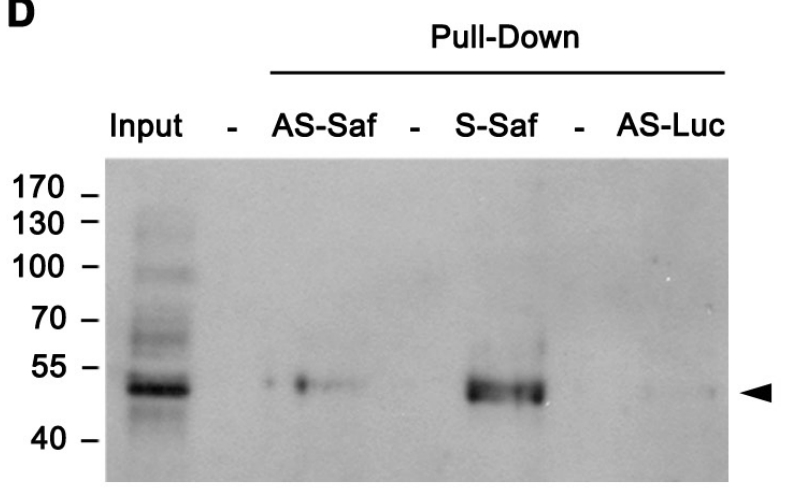

Figure 4: Saf directly interacts with splicing factor SPF45. A. Schematic of RNA pulldown experiments using K562 cells. B. Silver stained acrylamide gel of total nuclear proteins (input) or nuclear proteins pulled-down with biotin-labeled RNA for firefly luciferase (Luc; control) or Saf lncRNA in anti-sense (AS-Saf) and sense (S-Saf) orientations. M, molecular weight marker (kDal). C. Pie chart demonstrating functional clustering of 21 proteins found to interact with Saf by mass spectrometry. D. Western blot of nuclear extracts (input) recovered after pulldown of biotin-labeled AS- or S-Saf and reacted with SPF45 antibodies. Molecular weights (kDal) are indicated. 
A

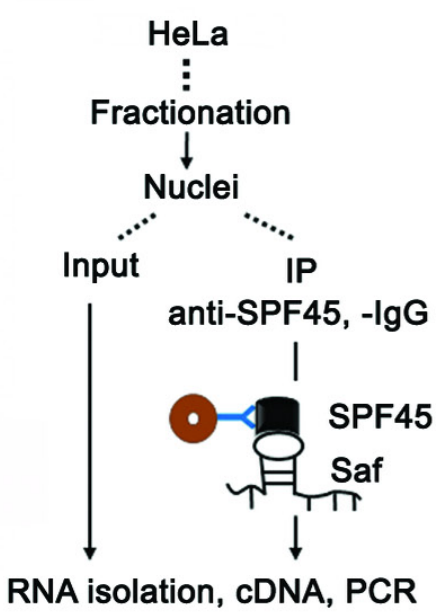

\section{C}
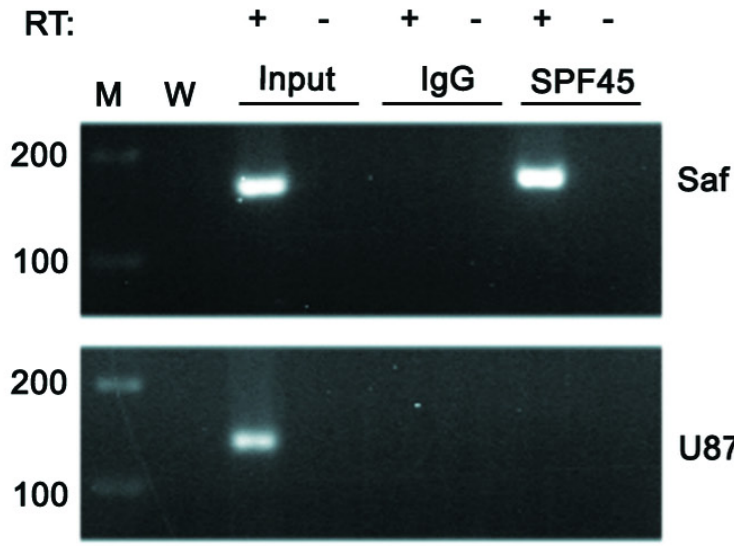

B

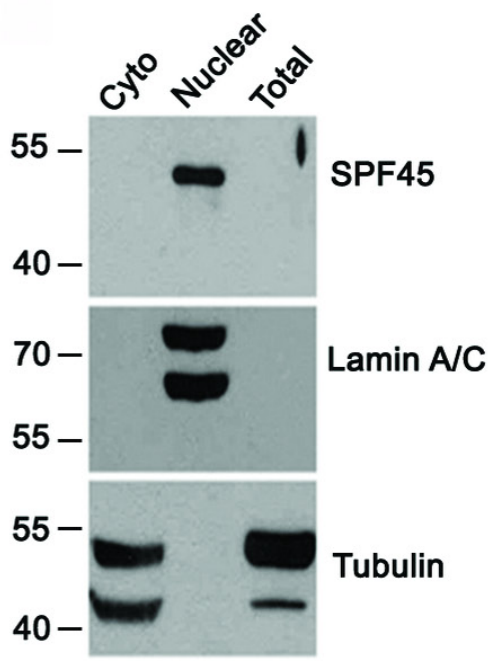

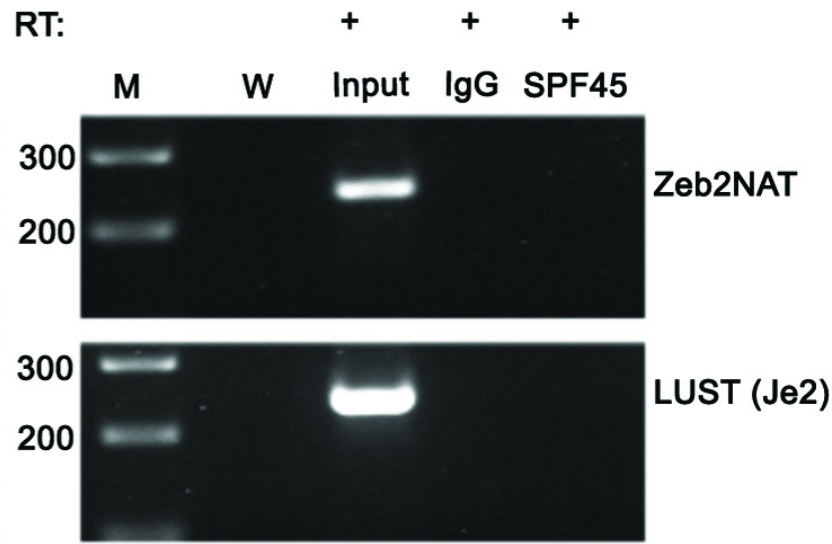
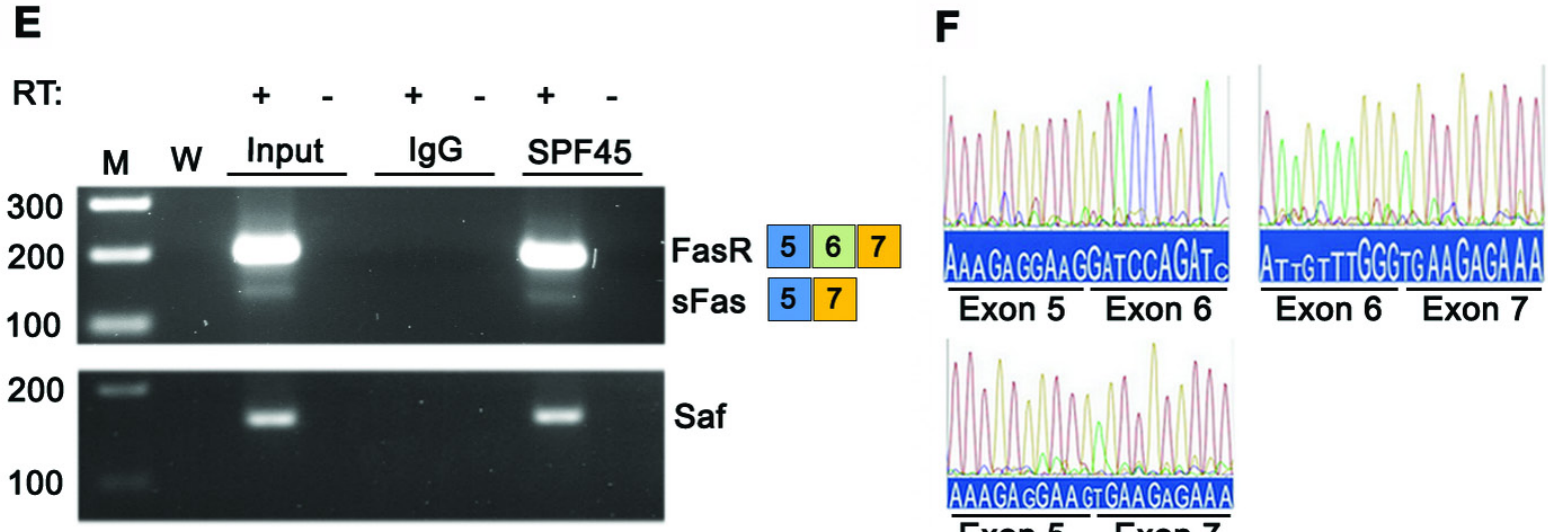

Exon 5 Exon 7

Figure 5: SPF45 interacts with Saf and Fas receptor transcripts. A. Schema for RNA co-immunoprecipitation experiments performed using nuclear extracts from HeLa cells, which have endogenous expression of Saf. B. Western blot of cytoplasmic (cyto), nuclear, or total cell lysates using antibodies to SPF45, Tubulin, or Lamin A/C. Molecular weights (kDal) are indicated. C. RNA isolated from nuclear extracts before (Input) and after immunoprecipitation with control IgG or SPF45 antibodies and RT-PCR performed with (+) and without (-) reverse transcription (RT) using primers for Saf, the snoRNA U87, or D. two nuclear lncRNAs, Zeb2NAT or LUST (Je2), or E. primers to exons 5 and 7 of Fas. M, 100-bp ladder; W, no template. F. Chromatograms of sequencing results for amplicons generated for Fas (Exons 5, 6, and 7) and soluble Fas (sFas, Exons 5 and 7) with exon junctions indicated. 
mRNA splicing, and specifically in Fas exon 6 exclusion by a mini-gene assay $[29,30]$. The ability of SPF45 to bind Saf was confirmed by repeating the RNA pull-down experiments and performing western blots (Figure 4D).

Additional confirmation of a specific interaction between Saf and SPF45 was tested by RNA coimmunoprecipitation (RIP) of fractionated cell lysates reacted with antibodies to SPF45 and RT-PCR of recovered RNA (Figure 5A). Western blot demonstrated nuclear localization of SPF45 and verified fraction purity (Figure 5B). Saf lncRNA co-precipitated with SPF45 protein (Figure 5C); however, the small nucleolar RNA U87 (Figure 5C) and two other nuclear lncRNAs also expressed from intronic sequences (LUST and Zeb2NAT; http://www.lncrnadb.org) were not detected (Figure 5D). Therefore, Saf and SPF45 specifically interact, suggesting a functional link to Fas pre-mRNA. This was validated by our ability to detect co-precipitated SPF45 and Fas mRNA with and without exon 6 (Figure 5E), and confirmed

A

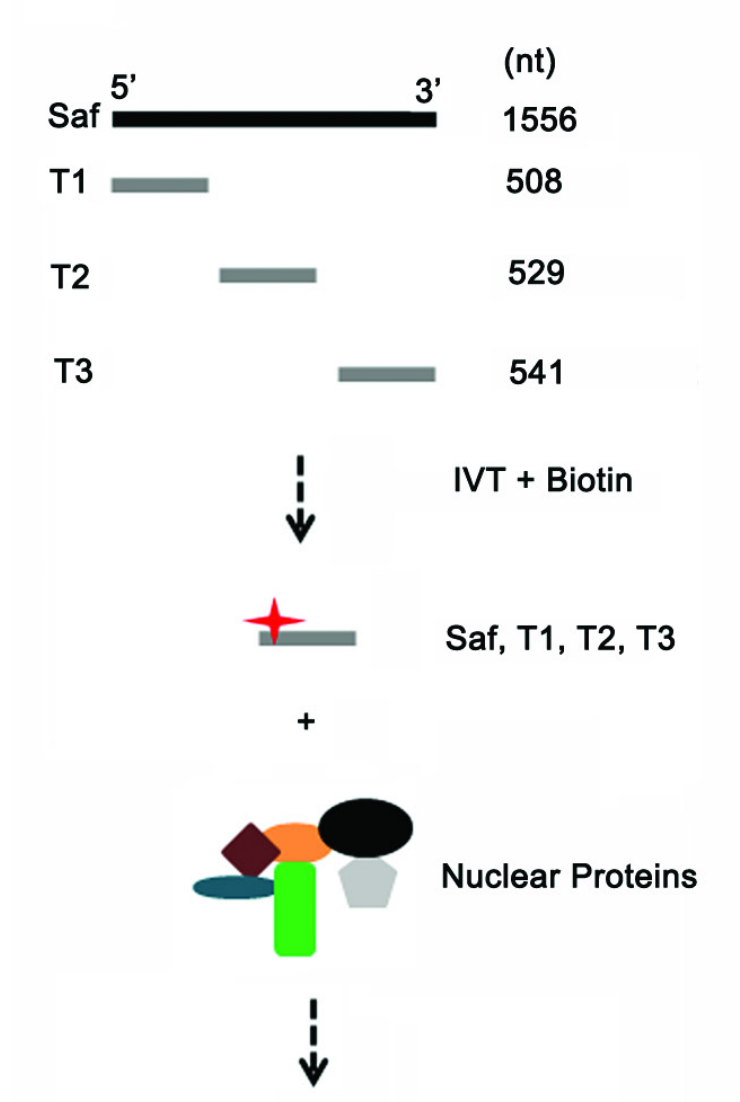

RNA Pull-Down, Silver stain, Western Blot through sequence analysis (Figure 5F).

To further validate the interaction between Saf and SPF45 and determine whether SPF45 interacts with a specific region of Saf, we performed RNA pulldown experiments with truncated versions of Saf (Figure 6A). Nuclear lysates and proteins bound to Saf RNA fragments were separated by SDS-PAGE and visualized with silver stain (Figure 6B) or subjected to western blot for SPF45 (Figure 6C). These assays revealed that the greatest degree of interaction is mediated by sequences located within the first 1037-bp of Saf. Together, the RNA pulldown, RNA immunoprecipitation, and deletion mapping results demonstrate a specific association between SPF45 and Saf.

\section{SPF45 knockdown reduces Fas splicing and sensitizes cells to Fas-mediated apoptosis}

The functional role of SPF45 on Fas alternative splicing was tested by knocking down SPF45 expression
Figure 6: Mapping SPF45-Saf interacting domains. A. Schematic diagram of RNAs corresponding to different fragments of Saf (T1, T2, or T3) produced by in vitro transcription (IVT) in the presence of biotin for RNA pulldown experiments. B. Silver stain acrylamide gel of total nuclear proteins before (Input) and after pulldown with biotin-labeled RNAs for firefly luciferase (Luc, control), full-length Saf, or truncated Saf fragments (T1, T2, T3). M, molecular weight marker (kDal). C. Western blot of nuclear extracts (input) recovered after pulldown of biotin-labeled Luciferase (Luc), full-length Saf, or truncated Saf transcripts reacted with SPF45 antibodies. Molecular weights $(\mathrm{kDal})$ are indicated.
B

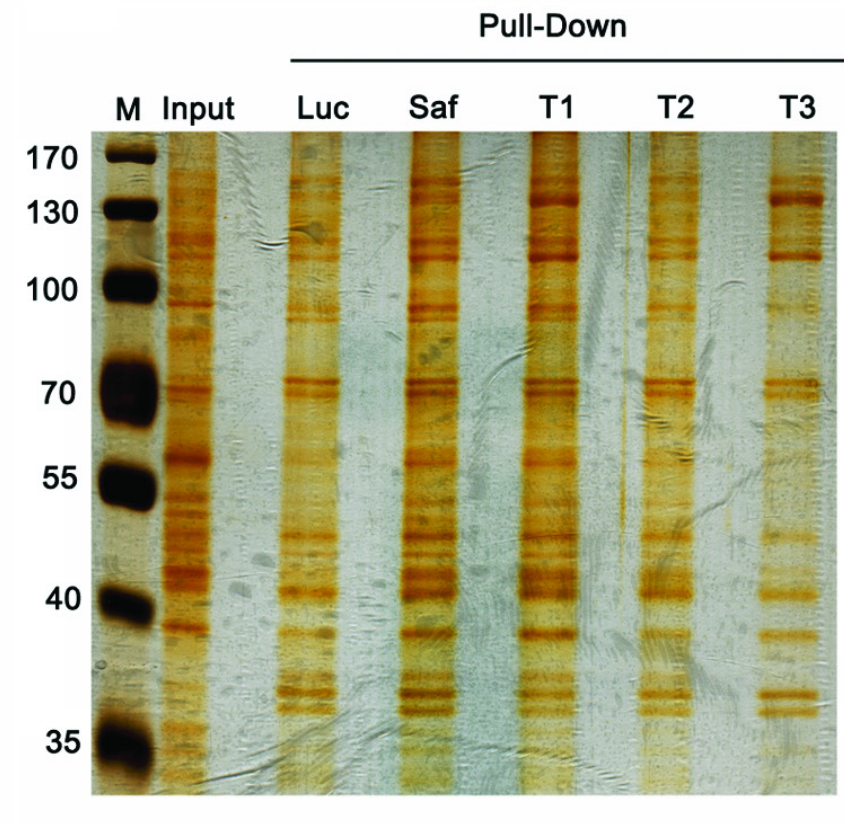

C

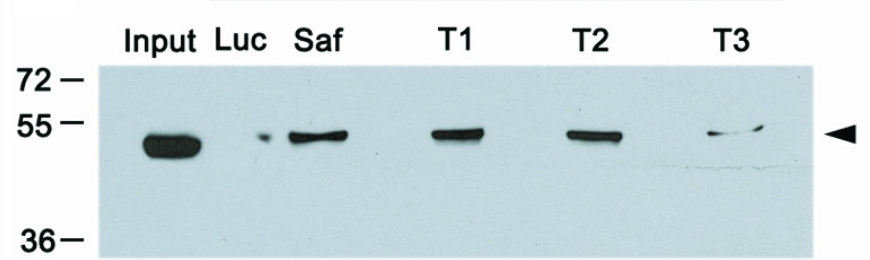


through lentivirus delivery of SPF45 shRNA. SPF45 mRNA levels were determined in cell lines generated from five SPF45 shRNAs and a non-targeting shRNA control (Supplementary Table S3). One shRNA reduced SPF45 transcripts by 69\% (Supplementary Table S3 and Figure $7 \mathrm{~A}$ ) and protein ( $45 \mathrm{kDa}$ band) by $90 \%$ (Figure 7B) and was selected for further study. We hypothesized that loss of SPF45 would have the opposite effect on Fas pre-mRNA splicing as Saf over-expression. This proved correct as evidenced by enrichment for Fas mRNA containing the transmembrane-encoding exon 6 (Figure
7C) and cell surface expression of Fas (Figure 7D; MFI: $1131 \pm 234 \mathrm{SPF} 45 \mathrm{KD}$ versus $630 \pm 187$ control, mean $\pm \mathrm{SD}$., $n=3, p<0.05)$. Therefore, SPF45 functions in a similar manner to Saf to regulate Fas exon 6 alternative splicing.

The biological relevance of altered Fas alternative splicing was determined by testing the ability of a Fas agonistic antibody (CH-11) to cause apoptosis of SPF45 knockdown cells. SPF45 knockdown cells demonstrated an increased sensitivity to Fas-mediated signals when compared to non-targeting shRNA control

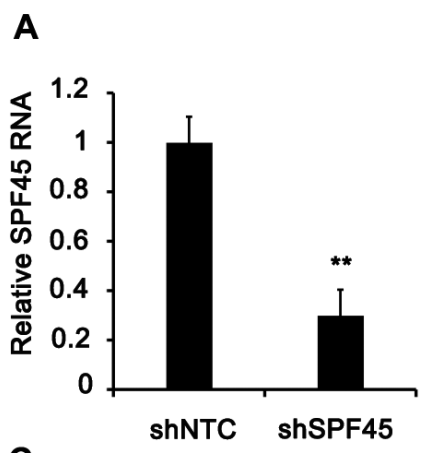

C

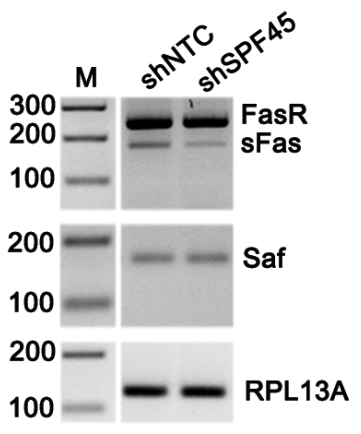

E

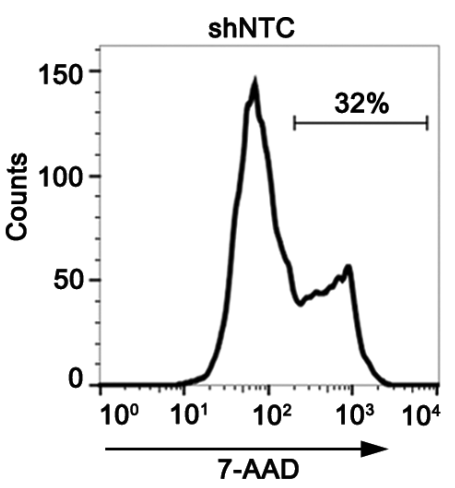

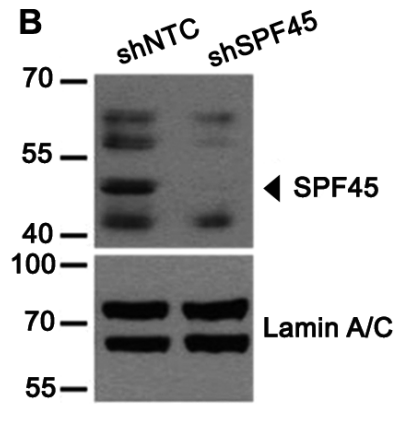
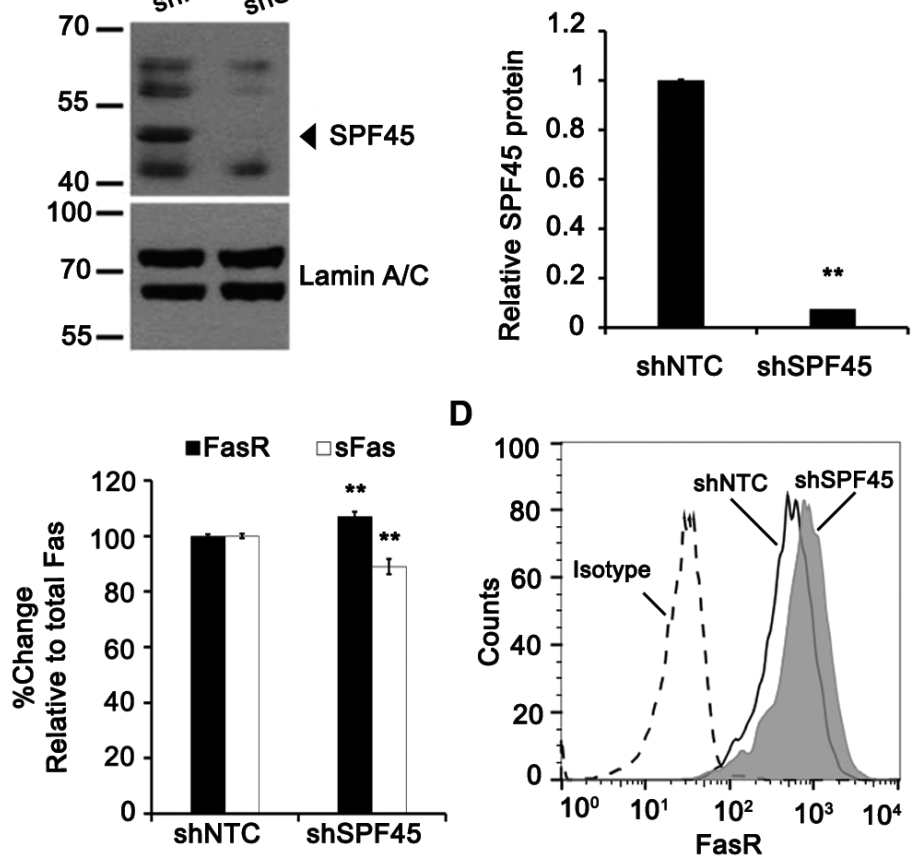

D
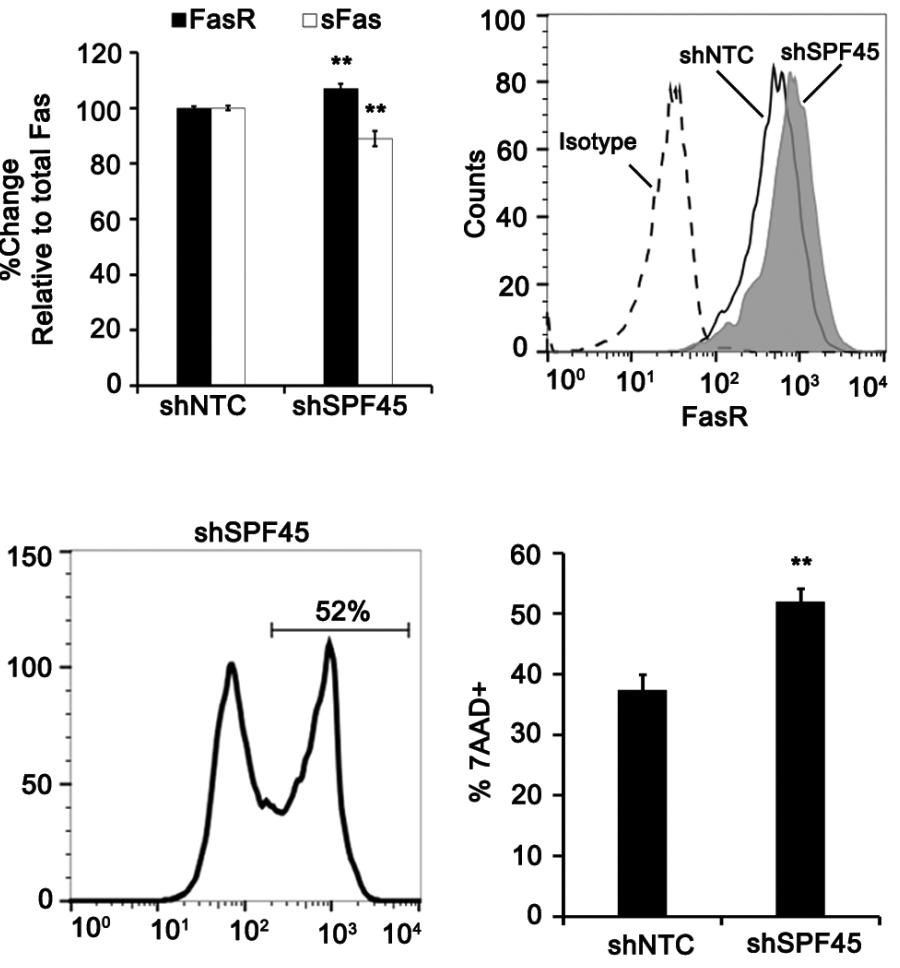

Figure 7: SPF45 knockdown impairs production of soluble Fas and enhances Fas-mediated apoptosis. HeLa cells stably expressing shRNA sequences for SPF45 (shSPF45) or a non-targeting control (shNTC) was screened for expression of SPF45 by A. Real time quantitative RT-PCR and B. Western blot (left), quantitation (right). C. Inverse agarose gel images of RT-PCR products from shNTC and shSPF45 cell lines transfected with plasmids encoding a Fas mini-gene (left). M, 100-bp ladder. Densitometry analysis of spliced Fas mRNA products normalized to RPL13A and reported as percent change relative to total Fas (right). D. Representative flow cytometry histograms demonstrating surface levels of Fas for shNTC and shSPF45 cell lines reacted with isotype control or anti-Fas antibodies. E. Left, representative flow cytometry histograms of 7-AAD incorporation in shNTC and shSPF45 cell lines treated overnight with anti-Fas activating antibody (clone $\mathrm{CH} 11 ; 100 \mathrm{ng} / \mathrm{mL}$ ). Right, percentage of 7-AAD positive cells by flow cytometry. Results are plotted as mean + $\mathrm{SD}$ for at least three independent experiments. * indicates $p<0.05$; ** indicates $p<0.001$ determined by Student's $t$-test. 
cells (Figure 7E; \% 7-AAD positive: $52 \pm 2 \%$ versus $37 \pm 3 \%$, respectively). Therefore, reduction of SPF45 sensitizes cells to Fas signals and leads to increased cell death, supporting the hypothesis that the Saf-SPF45 axis modulates Fas exon 6 alternative splicing.

\section{Overexpression of Saf in SPF45 knockdown cells does not rescue Fas pre-mRNA splicing}

To this point, our data demonstrate that independent modulation of Saf or SPF45 influence Fas pre-mRNA

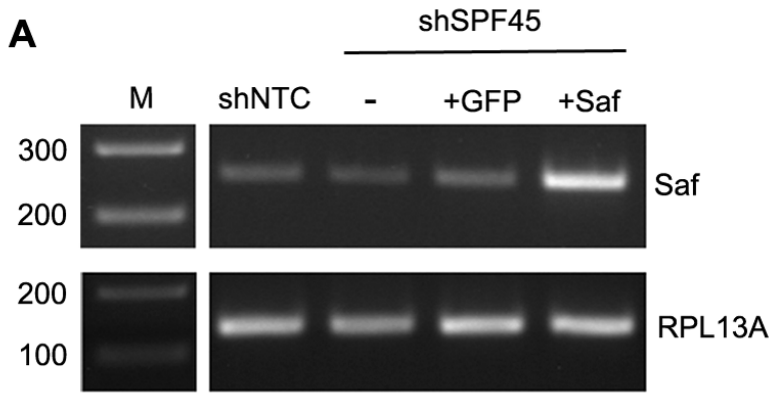

\section{B}

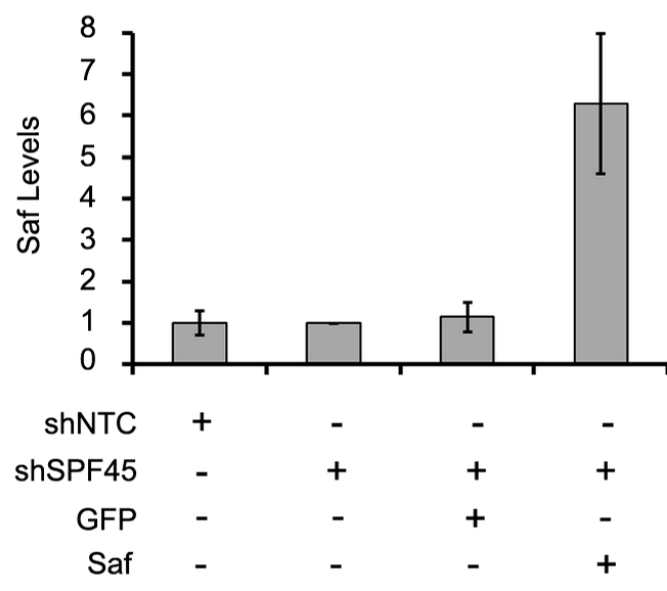

C

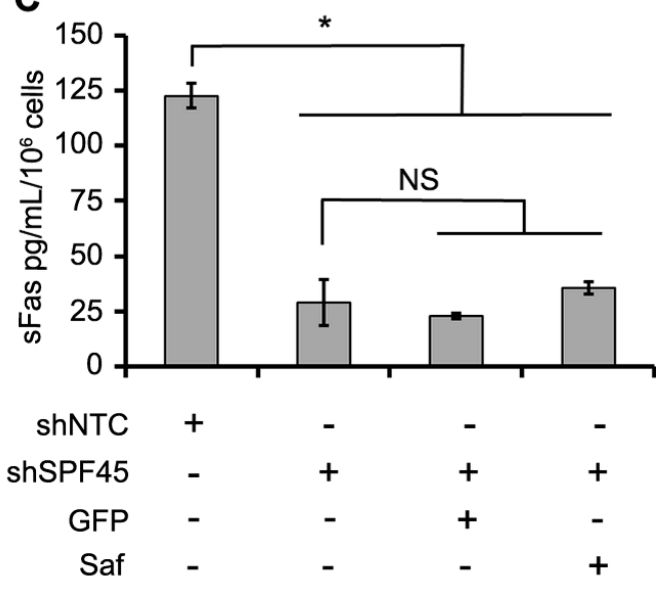

Figure 8: Saf overexpression in SPF45 knockdown cells does not rescue production of soluble Fas. A. Agarose gel images of Saf transcripts in shNTC stable cells (shNTC; control) and shSPF45 stable cells without transduction (-) or transduced with lentivirus encoding for expression of GPF (+GFP) or Saf/GFP (+Saf) and sorted for GFP expression. B. Quantitative real time PCR analysis of Saf levels in the same cell lines, demonstrating an approximately 6-fold increase in Saf expression in the Saf transduced shSPF45 cells. C. Conditioned medium for the same cell lines assayed for soluble Fas (sFas) by ELISA. All quantitative results are plotted as mean \pm SD. for at least three independent experiments. * indicates $p<0.05$; NS indicates not significant determined by one way ANOVA with NewmanKeuls post-hoc test. Vertical white lines have been inserted to represent repositioned lanes on the gel images. 
splicing, altering the production of Fas proteins (full length Fas or sFas). To verify that Saf and SFP45 interact to stimulate Fas exon 6 skipping, we performed a modified rescue experiment by over-expressing Saf in SPF45 knockdown cells. HeLa cells engineered with SPF45 shRNA were transduced with lentivirus encoding for GFP or Saf/GFP, and the GFP fraction enriched by FACS. Endpoint and quantitative RT-PCR confirmed Saf over-expression $(6.3 \pm 1.7$-fold increase) when compared to cells expressing the non-targeting shRNA, SPF45 knockdown cells not transduced with lentivirus, and SPF45 knockdown cells transduced with the GFPencoding lentivirus (Figure 8A and 8B). Production of sFas was assayed by ELISA to determine whether overexpression of Saf could rescue the splicing defect induced by SPF45 knockdown. sFas levels were significantly decreased in supernatants collected from SPF45 knockdown cells when compared to non-targeting shRNA controls (Figure $8 \mathrm{C}$; sFas in $\mathrm{pg} / \mathrm{mL} / 10^{6}$ cells: shNTC control $123 \pm 6$; shSPF45 $29 \pm 10 ; p<0.05 ;$ mean \pm s.d., $n=4$ ), confirming our previous results that alternative splicing of Fas was reduced by SPF45 knockdown. However, Saf over-expression in SPF45 knockdown cells had no statistically significant effect on production of sFas when compared to SPF45 knockdown cells that were not transduced (shSPF45 above) or GFP transduced (Figure $8 \mathrm{C}$, shSPF $45 \mathrm{KD} \pm$ GFP: $23 \pm 1$; shSPF $45 \mathrm{KD} \pm$ Saf: 36 $\pm 3 \mathrm{pg} / \mathrm{mL} / 10^{6}$ cells, mean \pm s.d., $\left.n=4\right)$. These findings indicate that elevated levels of Saf are not sufficient to enhance Fas splicing when SPF45 is limited, and support the hypothesis that Saf and SPF45 co-participate in modulating Fas pre-mRNA splicing and the production of full length or sFas, thereby altering apoptosis.

\section{DISCUSSION}

RNA is flexible and can assume a variety structures that allow it to interact with other RNAs, DNA and proteins. This unique feature allows RNA to perform a range of important regulatory roles in the cell, including pre-mRNA splicing. LncRNAs are known to function in pre-mRNA splicing through various mechanisms. Examples of these lncRNAs include several natural antisense transcripts (NATs) [31-34], repeat-containing lncRNAs [35], and the intergenic lncRNA lung adenocarcinoma transcript 1 (MALAT1) [20]. Some responsible mechanisms include RNA:RNA duplexing $[31,36]$ with overlapping sense transcripts and regulation of functional levels of splicing factors [20]. We demonstrated that Saf is localized to the nucleus, but over-expression had limited effects on genome-wide transcription. We found that Saf interacted with Fas premRNA at regions that flank the transmembrane domain (exon 6) and splicing factor SPF45 to regulate production of a $\mathrm{sFas}$ protein which protected cells from Fas-mediated apoptosis. Production of sFas was dependent upon expression of both Saf and SPF45.

Alternative splicing is a regulated process that

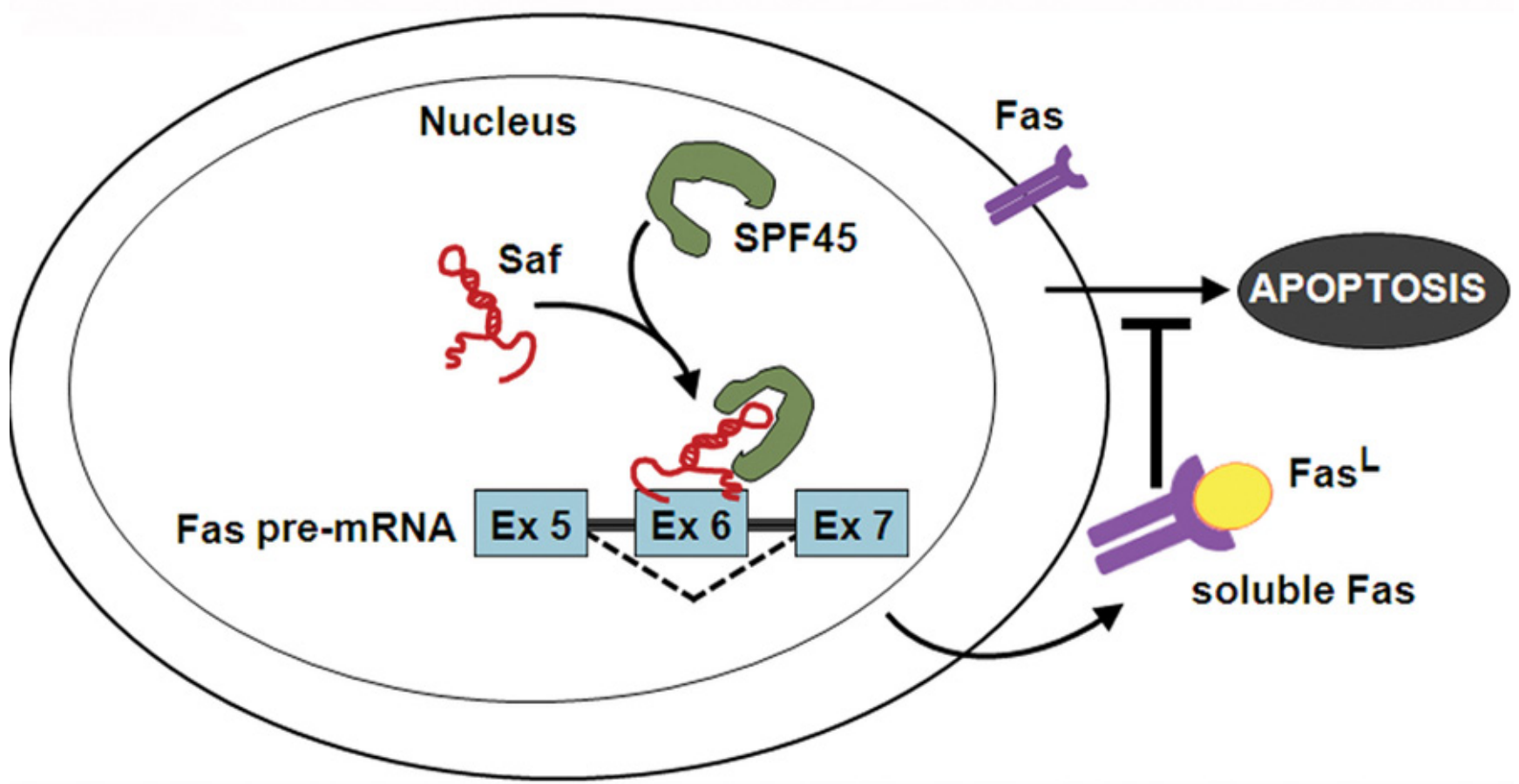

Figure 9: Model of Saf and SPF45 in attenuating Fas-mediated apoptosis. LncRNA Saf guides SPF45 to Fas receptor (Fas) pre-mRNA, specifically to the exon 6 (Ex 6) region, facilitating removal of transmembrane sequences by alternative splicing. The result is diminution of Fas on the cell surface and increased production of soluble Fas that sequesters Fas ligand $\left(\right.$ Fas $\left.^{\mathrm{L}}\right)$ and renders cells less sensitive to Fas-mediated apoptosis. 
results in the generation of distinct proteins from a single primary transcript [37]. Fas pre-mRNA is alternatively spliced to produce a number of soluble isoforms [38]; the most abundant, well-studied isoform, Fas $\Delta \mathrm{Ex} 6$, lacks the hydrophobic transmembrane-spanning domain $[21,39]$. This soluble version of Fas can bind FasL in the extracellular space and impair normal signaling [21, 39]. Dysregulation of the Fas signaling pathway is seen in numerous pathological conditions, including cancer, neurological, cardiovascular, infectious/viral, autoimmune and hematopoietic disease. We show that Saf interacts with Fas pre-mRNA at regions that flank exon 6, and that Saf levels influence production of sFas. These effects could cause abnormal Fas signaling and pathology in any of the aforementioned conditions.

LncRNAs have been identified to either promote [40-42] or inhibit [5, 43] apoptosis, through mechanisms that include alternative splicing of a pre-mRNA. Furthermore, alternatively spliced gene products are known to play important roles in promoting or preventing cell death [44]. Regulation of Fas alternative splicing has been demonstrated through proteins that promote exclusion of exon 6 [45]. One of these proteins is SPF45, a component of splicing complexes. Expressed at low levels in most tissues, SPF45 functions in the recognition and activation of the 3 ' splice site AG within introns [29]. SPF45 over-expression is seen in breast, ovarian, bladder, colon, lung, pancreatic, and prostate cancer with proposed roles in proliferation and chemotherapy resistance [46] as well as cell migration and invasion [47]. We show that SPF45 directly interacts with Saf to promote alternative splicing of Fas. Furthermore, knockdown of SPF45 decreased alternative splicing of Fas pre-mRNA translating to reduced sFas production, accumulation of Fas on the cell surface, and increased sensitivity to Fasdependent apoptosis. While the role of SFP45 in Fas exon 6 alternative splicing is well characterized, SPF45 is also involved in alternative splicing of many other premRNAs. The mechanism by which a single splicing factor is targeted to a specific pre-mRNA and exon/intron border is not well known, but we propose that lncRNA Saf acts to recruit SPF45 to Fas pre-mRNA, specifically to the exon 6 region, to promote exon 6 exclusion. Regulation of this complex may depend upon post-translational modification of SPF45 where phosphorylation has been shown to regulate its role in alternative splicing of Fas $[30,47]$. As these are the first studies describing a role for a lncRNA in SPF45-mediated alternative splicing, our results suggest that IncRNAs with similar function are yet to be discovered. Sequence analysis of RNA immunoprecipitated with SPF45 or other splicing factors could identify lncRNAs with complementary function.

From our collective data, we propose a model where Saf interacts with Fas pre-mRNA to guide SPF45 to this unprocessed transcript and direct alternative splicing of Fas exon 6 (Figure 9). The result is increased production of sFas that protects cells against Fas-mediated apoptosis. This mechanism can be generalized to a wide-variety of cell types functioning in normal or disease conditions to include control of erythropoiesis [48], depletion of antigenactivated T cells [49], development of acute leukemia [50], survival of leukemic large granular lymphocytes [51], and autoimmune lymphoproliferative disorder (ALPS) [52], where increased production of sFas has been suggested to block apoptosis. Further characterization of the interaction between Saf, SPF45, and Fas pre-mRNA may reveal additional levels of complexity and present novel strategies aimed at re-establishing proper Fas signaling in a variety of pathological conditions.

\section{MATERIALS AND METHODS}

\section{Vector construction}

Saf lncRNA lentivirus. Total RNA (350ng) isolated from bone marrow $\mathrm{CD} 34^{+}$cells was reverse transcribed (High Capacity RT kit; Applied Biosystems) with a primer corresponding to the 3'-end of Saf (Supplementary Table S1A). cDNA $(1 \mu \mathrm{g})$ was PCR amplified using Saf lncRNA primers (Supplementary Table S1A) and Phusion HiFidelity Taq polymerase (Fermentas). A 1536-bp amplicon representing the full length Saf lncRNA was gel extracted (QIAquick, Qiagen), A-tailed and inserted into pCR2.1 TOPO/TA (Invitrogen) to create pCR2.1/Saf and sequence verified (GenScript). Tth111I (5') and AgeI (3') restriction sites were introduced by PCR (primers: Supplementary Table S1A) and a Tth111I to AgeI fragment subcloned between the murine stem cell virus (MSCV) and human phosphoglycerate kinase (hPGK) promoters in pCL20c/ MSCV-hPGK-GFP lentiviral vector. The resulting vector directs expression of lncRNA Saf under control of the MSCV promoter and independently expresses GFP under control of the hPGK promoter and was used to prepare lentiviral particles.

Saf IncRNA in vitro transcription. The T3 promoter binding sequence ( $\left.5^{\prime}\right)$ and NotI restriction site (3') were introduced by PCR (primers: Supplementary Table S1A) into pCR2.1/Saf to create pCR2.1/Saf in vitro and used for Saf in vitro transcription.

\section{Cell culture and transfection}

Human embryonic kidney (HEK) 293T, erythroleukemia K562, Jurkat T cells, and HeLa cervical carcinoma cells were cultured in DMEM (Mediatech) supplemented with $10 \%$ (v/v) fetal bovine serum (FBS; HyClone laboratories) and antibiotics. Plasmids were transfected using Lipofectamine 2000 (Invitrogen) and analyzed 24 hours later. 


\section{Western immunoblot}

Whole cell lysates, prepared with M-PER plus HALT protease inhibitors (Thermo Scientific), were separated by SDS-PAGE and transferred onto PVDF membranes (Immobilon-P, Millipore). Primary antibodies recognizing SPF45 were from Santa Cruz Biotechnology; GAPDH antibodies were from Sigma; Lamin A/C and $\alpha$-tubulin were from Active Motif. HRP-conjugated secondary antibodies were from Thermo Scientific.

\section{Subcellular fractionation}

Cells were lysed with a buffer containing $50 \mathrm{mM}$ $\mathrm{KCl}, 25 \mathrm{mM}$ HEPES (pH 7.8), $1 \mathrm{mM}$ phenylmethylsulfonyl fluoride (PMSF), $10 \mu \mathrm{g} / \mathrm{mL}$ leupetin, $25 \mu \mathrm{g} / \mathrm{mL}$ aprotinin, $100 \mu \mathrm{M}$ dithiothreitol (DTT) and $0.5 \% \mathrm{NP}-40$, and the resulting lysates centrifuged at 2,700 $\mathrm{x} g$ for $5 \mathrm{~min}$ at $4^{\circ} \mathrm{C}$. The supernatant was used as the cytosolic fraction. Pelleted material was washed, incubated in nuclear extraction buffer $(500 \mathrm{mM} \mathrm{KCl}, 1.5 \mathrm{mM} \mathrm{MgCl}, 25 \mathrm{mM}$ HEPES, $1 \mathrm{mM}$ PMSF, $10 \mu \mathrm{g} / \mathrm{mL}$ leupeptin, $25 \mu \mathrm{g} / \mathrm{mL}$ aprotonin, $100 \mu \mathrm{M}$ DTT and $10 \%$ glycerol) on ice for 30 $\mathrm{min}$ and the nuclear fraction collected by centrifugation at $20,000 \times g$ for $10 \mathrm{~min}$ at $4^{\circ} \mathrm{C}$.

\section{Saf IncRNA subcellular localization}

Cells were separated into cytoplasmic and nuclear fractions and RNA (50ng) isolated from each fraction reverse transcribed into cDNA as described above. End point PCR (30 cycles) was performed using cDNA (100ng), PCR Master Mix (Thermo Scientific), and primers to 47S pre-rRNA, U87, Saf, or RPL13A (Supplementary Table S1B). Amplified products were resolved on 3\% TAE-agarose gel containing ethidium bromide and photographed. Quantitative PCR (qPCR) was performed on a StepOne Plus thermocycler (Applied Biosystems) using cDNA (100 ng), iTaq Universal SYBR Green Super Mix (BioRad), and primers to 47S pre-rRNA, U87, or Saf, and normalized to RPL13A (Supplementary Table S1B).

\section{Saf IncRNA in vitro transcription}

Sense (T3) and anti-sense (T7) biotinylated (Bio16-UTP, Life Technologies) Saf lncRNA transcripts were generated from pCR2.1/Saf in vitro (MegaScript, Ambion). Unlabeled Saf RNA was prepared in the absence of bio-16-UTP. RNA was precipitated with lithium chloride and stored at $-80^{\circ} \mathrm{C}$.

\section{RNAse A protection assay}

HeLa cells $\left(20 \times 10^{6}\right)$ were fractionated as described above and nuclear extracts treated with Proteinase K $(0.1$ $\mu \mathrm{g}$ ) for 90 minutes at $42^{\circ} \mathrm{C}$ before being isolated of total RNA (Purelink RNA mini kit, Ambion). An aliquot of RNA was stored at $-20^{\circ} \mathrm{C}$ to be used as input control in the PCR analysis. RNA was mixed with yeast tRNA (Sigma) pre-blocked magnetic streptavidin beads (Invitrogen) and biotin-labeled Saf $(8 \mu \mathrm{g})$. Reactions were incubated overnight at $4^{\circ} \mathrm{C}$ with end-over-end rotation. The following day, samples were washed (100 mM HEPES $\mathrm{pH} 7.8,500 \mathrm{mM} \mathrm{LiCl}, 10 \mathrm{mM}$ EDTA, and $10 \mathrm{mM}$ DTT). RNA was separated into two tubes and one sample treated with RNAse A (7 units; ActiveMotif) for 30 minutes at $37^{\circ} \mathrm{C}$ to digest single-stranded RNA. Samples were heat inactivated $\left(95^{\circ} \mathrm{C}\right.$ for 10 minutes) and cDNA prepared as described above. The cDNAs $(1 \mu \mathrm{g})$ were PCR amplified for 40 cycles using PCR Master Mix (Thermo Scientific) and primers designed to recognize exon and intron sequences of Fas pre-mRNA with products ranging from $\sim 275$-bp to 660-bp (Supplementary Table S1C). Amplified products were resolved on 3\% TAE-agarose gel containing ethidium bromide and photographed.

\section{RNA pull-down, silver stain and mass spectrometry}

RNA pull-down was performed according to [53]. Nuclear extracts were obtained from K562 cells as described above. Extracts $(\sim 300 \mu \mathrm{g})$ were mixed with denatured RNA ( $8 \mu \mathrm{g}$ ) corresponding to unlabeled Saf (sense) or biotinylated anti-sense or sense Saf and the mixtures incubated overnight at $4^{\circ} \mathrm{C}$ with yeast tRNA (Sigma) pre-blocked streptavidin beads (Invitrogen). Beads were collected by centrifugation at 20,000 x g for 1 $\min$ at $4^{\circ} \mathrm{C}$ and protein samples separated by SDS-PAGE. Resolved proteins were visualized using silver stain (Pierce).

For mass spectrometry, immunoprecipitated proteins were separated by SDS-PAGE, gel pieces digested with trypsin and peptides injected with the assistance of Genomic Solutions robotic system. Peptides were eluted and identified using a tandem time-of-flight mass spectrometer (4700 Proteomics Analyzer; Applied Biosystems). The raw data was searched in Mascot, SEQUEST or Protein Prospector against the human subset of the SwissProt database. Saf-protein interactions were confirmed by repeating the RNA-pulldown experiments and immunoprecipitated complexes verified by western blot. 


\section{RNA co-immunoprecipitation (RIP)}

Immunoprecipitation of endogenous proteinRNA complexes was performed using HeLa cell nuclear extracts (described above). Extracts were incubated with anti-SPF45 and protein A/G magnetic beads (Thermo Scientific) overnight at $4^{\circ} \mathrm{C}$. RNA was isolated from the precipitated complexes and reverse transcribed (Life Technologies). RT-PCR was performed using cDNA (1 $\mu \mathrm{g}$ ), PCR Master Mix (Thermo Scientific), and primers to Saf, U87, Zeb2NAT, Lust, or Fas (Supplementary Table S1B). Amplified products were resolved on 3\% TAE-agarose gel, stained with ethidium bromide and photographed.

\section{Saf IncRNA overexpression}

Lentiviral vector particles pseudotyped with vesicular stomatitis virus $\mathrm{G}$ protein (VSV-G) were prepared for pCL20c/Saf-ires-GFP or pCL20c/ires-GFP by transient transfection of HEK293 T cells using the calcium phosphate precipitation technique [54]. Vector preparations were titered on K562 cells based on GFP expression as determined by flow cytometry. Cells were transduced at multiplicity of infection (m.o.i.) of 1, 3, or 10 in the presence of polybrene $(8 \mu \mathrm{g} / \mu \mathrm{L}$; Sigma). Transduced cell populations were enriched by FACS (FACSAria, BD Biosciences) based on GFP expression after 5-7 days. For select experiments, cells were further separated into GFP-low and GFP-high populations by FACS. Saf levels were determined by end-point RT-PCR to verify coordinate expression patterns between GFP and Saf in these populations.

\section{Microarray analysis}

Total RNA was isolated from FACS enriched GFP (control) and Saf/GFP lentiviral transduced Jurkat T cells and K562 cells. RNA (100 ng) was reverse transcribed into cDNA using 3' IVT Express kit (Affymetrix) and hybridized to an HG-U133_Plus2 cartridge (Affymetrix) permitting analysis of over 47,000 transcripts. Gene expression values were calculated by robust means analysis (RMA) model with simple fold-change applied to identify differential expression and the $\log _{2}$ normalized intensity of filtered probes plotted for each cell type. All microarray data have been deposited in the Gene Expression Omnibus (http://www.ncbi.nlm.nih.gov/geo/).

\section{Saf IncRNA knockdown by siRNA}

A pool of four siRNAs specific for Saf or nontargeting siRNAs (Lincode siRNA, Thermo Scientific) were transfected into $\mathrm{HeLa}$ cells at $75 \mathrm{nM}$ using
DharmaFECT 1 (Thermo Scientific). Cells were incubated for 48 hours then RNA was isolated using PureLink RNA mini kit (Invitrogen) and reverse transcribed into cDNA (VILO; Life Technologies). RT-PCR was carried out using cDNA (100 ng), PCR Master Mix (Thermo Scientific), and primers to Saf or RPL13A (Supplementary Table S1B). Amplified products were resolved on 3\% TAE-agarose gel stained with ethidium bromide and photographed. Quantitative PCR (qPCR) was performed as described above for Saf and normalized to RPL13A.

\section{SPF45 shRNA knockdown}

Five lentiviral vector constructs encoding for expression of shRNA sequences specific to SPF45 (Supplementary Table S3) were purchased from The RNAi Consortium (Sigma). Control shRNAs specific to placenta growth factor (Sigma) were obtained through Dr. Donald Torry (SIU School of Medicine). Lentivirus particles were generated and HeLa cells transduced as described above. Stable cell lines were selected with puromycin $(0.5 \mu \mathrm{g} / \mathrm{mL})$; pools of puromycin-resistant cells were evaluated by qPCR and western blot for SPF45 mRNA and protein levels, respectively, compared to non-targeting control shRNA expressing cells. From these studies, clone TRCN0000231429 was selected for use in the knockdown studies (Supplementary Table S3).

\section{Quantification of end-point PCR products}

Agarose gels were photographed with a BioDocIt 220 Imaging System equipped with a 1.3 megapixel camera (UVP, Analytik Jena) and images acquired as TIFFs. Images were inverted (Adobe Photoshop) and the number of pixels in each band measured using ImageJ.

\section{Flow cytometry analysis}

Flow cytometry studies were performed on FACSCalibur or FACSAriaII (BD Biosciences) using CellQuest v5.2.1 or FlowJo v10.0 analysis software to monitor the following:

Fas receptor. HeLa cells were reacted with APC-conjugated mouse anti-human CD95 (DX2, BD Biosciences); mouse anti-human IgG-APC was used as an isotype control. The geometric mean of fluorescence intensity (MFI) was determined for each condition.

Apoptosis. HeLa cells were treated overnight with $100 \mathrm{ng}$ anti-Fas activating antibody (CH-11, Millipore), washed with PBS, incubated with 7-amino-actinomycin $\mathrm{D}$ (7-AAD, Millipore) for five minutes and the percent 7-AAD positive cells determined. 


\section{Soluble Fas (sFas) ELISA}

Conditioned supernatants were collected from HeLa cells 48 to 72 hours after plating, and used immediately or stored at $-20^{\circ} \mathrm{C}$. Adherent cells were harvested with trypsin and viable counts performed by trypan blue exclusion. Supernatants were assayed for sFas by ELISA (R\&D Systems) according to the manufacturer's protocol and optical density measured at $450 \mathrm{~nm}$ using a Multiskan Spectrum ELISA reader (Thermo Scientific). Levels of sFas are expressed as $\mathrm{pg} / \mathrm{mL} / 10^{6}$ viable cells.

\section{Statistical analysis}

Microsoft Excel or Prism 5 (GraphPad) was used to determine descriptive statistics (mean $\pm \mathrm{SD}$ ) and significant differences between mean values determined by unpaired Student's $t$-test (two-tailed) or one-way ANOVA with Newman-Keuls post-hoc test. P-values are indicated by asterisks in the figures with level of significance reported.

\section{ACKNOWLEDGMENTS}

We thank Dr. Tom Griffith (Department of Urology, University of Minnesota, Minneapolis, MN), Dr. Dan Kaufman (Department of Medicine and Stem Cell Institute, University of Minnesota, Minneapolis, MN), and Dr. Don Torry and Dr. Ed Gershburg (Department of Medical Microbiology, Immunology and Cell Biology, Southern Illinois University School of Medicine) for critical reading of this manuscript as well as the flow cytometry laboratory of Melissa Roberts for expertise in flow cytometry and cell sorting.

\section{GRANT SUPPORT}

This work was supported by a Medical Innovators Grant from the Doris Duke Charitable Foundation (D.A.P. and A.W.). The Southern Illinois University School of Medicine flow cytometry equipment was supported by Award Number S10RR025674 from the National Center for Research Resources. The funders had no role in study design, data collection and analysis, decision to publish, or preparation of the manuscript.

\section{CONFLICTS OF INTEREST}

The authors declare no conflict of interest.

\section{REFERENCES}

1. Trauth BC, Klas C, Peters AMJ, Matzuku S, Moller P, Falk W, Debatin KM, and Krammer PH. Monoclonal antibody mediated tumor regression by induction of apoptosis. Science. 1989; 245: 301-5.

2. Yonehara S, Ishii A, and Yonehara M. A cell killing monoclonal antibody (anti-Fas) to a cell surface antigen codownregulated with the receptor of TNF. J Exp Med. 1989; 169: 1747-56.

3. Suda T and Nagata S. Purification and characterization of the Fas ligand that induces apoptosis. J Exp Med. 1994; 179: 873-9.

4. Morris KV and Mattick JS. The rise of regulatory RNA. Nat Rev Genet. 2014; 15: 423-37.

5. $\mathrm{Hu} \mathrm{W}$, Alvarez-Dominguez JR, and Lodish HF. Regulation of mammalian cell differentiation by long non-coding RNAs. EMBO Reports. 2012; 13: 971-83.

6. Rinn JL and Chang HY. Genome regulation by long noncoding RNAs. Ann Rev Biochem. 2012; 81: 145-66.

7. Lee JT. Epigenetic regulation by long noncoding RNAs. Science. 2012; 338: 1435-9.

8. Kung JT, Colognori D, and Lee JT. 2013. Long Noncoding RNAs: Past, Present, and Future. Genetics. 2013; 193: 65169.

9. Paralkar VR and Weiss MJ. 2013. Long noncoding RNAs in biology and hematopoiesis. Blood. 2013; 121: 4842-6.

10. Li K and Ramchandran R. Natural antisense transcript: a concomitant engagement with protein-coding transcript. Oncotarget. 2010; 1: 447-52. doi: 10.18632/oncotarget.178.

11. Katayama S, Tomaru Y, Kasukawa T, Waki K, Nakanishi M, Nakamura M, Nishida H, Yap CC, Suzuki M, Kawai J, Suzuki H, Carninci P, Hayashizaki Y, et al. Antisense transcription in the mammalian transcriptome. Science. 2005; 309: 1564-6.

12. Carninci P, Kasukawa T, Katayama S, Gough J, Frith MC, Maeda N, Oyama R, Ravasi T, Lenhard B, Wells C, Kodzius R, Shimokawa K, Bajic VB, et al. The transcriptional landscape of the mammalian genome. Science. 2005; 309: 1559-63.

13. Nishizawa $M$, Okumura $T$, Ikeya $Y$, and Kimura $T$. Regulation of inducible gene expression by natural antisense transcripts. Front Biosci (Landmark Ed). 2012; 17: 938-958.

14. Guttman M and Rinn JL. Modular regulatory principles of large non-coding RNAs. Nature. 2012; 482: 339-46.

15. Pelechano V and Steinmetz LM. Gene regulation by antisense transcription. Nat Rev Genet. 2013; 14: 880-93.

16. Brantl S. Regulatory mechanisms employed by cis-encoding antisense RNAs. Curr Opin Microbiol. 2007; 10: 102-9.

17. Chen J, Sun M, Kent WJ, Huang X, Xie H, Wang W, Zhou G, Shi RZ, and Rowley JD. Over $20 \%$ of human transcripts might form sense-antisense pairs. Nucleic Acids Res. 2004; 32: 4812-20.

18. Gonzalez I, Munita R, Agirre E, Dittmer TA, Gysling K, Misteli T, and Luco RF. A lncRNA regulates alternative splicing via establishment of a splicing-specific chromatin 
signature. Nat Struct Mol Biol. 2015; 22: 370-6.

19. Geisler S and Coller J. RNA in unexpected places: long non-coding RNA functions in diverse cellular contexts. Nat Rev Mol Cell Biol. 2013; 14: 699-712.

20. Tripathi V, Ellis JD, Shen Z, Song DY, Pan Q, Watt AT, Freier SM, Bennett CF, Sharma A, Bubulya PA, Blencowe BJ, Prasanth SG, and Prasanth KV. The nuclear-retained noncoding RNA MALAT1 regulates alternative splicing by modulating SR splicing factor phosphorylation. Mol Cell. 2010; 39: 925-38.

21. Cascino I, Fiucci G, Papoff G, and Ruberti G. Three functional soluble forms of the human apoptosis-inducing Fas molecule are produced by alternative splicing. J Immunol. 1995; 154: 2706-13.

22. Yan MD, Hong CC, Lai GM, Cheng AL, Lin YW, and Chuang SE. Identification and characterization of a novel gene Saf transcribed from the opposite strand of Fas. Hum Mol Genet. 2005; 14: 1465-1474.

23. Batista PJ and Chang HY. Cytotopic localization by long noncoding RNAs. Curr Opin Cell Biol. 2013; 25:195-199.

24. Alló M, Buggiano V, Fededa JP, Petrillo E, Schor I, de la Mata M, Agirre E, Plass M, Eyras E, Elela SA, Klinck R, Chabot B, and Kornblihtt AR. Control of alternative splicing through siRNA-mediated transcriptional gene silencing. Nat Struct Mol Biol. 2009; 16: 717-24.

25. Busch A, Richeter AS, and Backofen R. 2008. IntaRNA: efficient prediction of bacterial sRNA targets incorporating target site accessibility and seed regions. Bioinformatics. 2008; 24: 2849-56.

26. Wright PR, Georg J, Mann M, Sorescu DA, Richter AS, Lott S, Kleinkauf R, Hess WR, and Backofen R. CopraRNA and IntaRNA: predicting small RNA targets, networks and interaction domains. Nucleic Acids Res. 2014; 42: W11923.

27. Jurica MS, Licklider LJ, Gygi SR, Grigorieff N, and Moore MJ. Purification and characterization of native spliceosomes suitable for three-dimensional structural analysis. RNA. 2002; 8: 426-39.

28. Will CL and Luhrmann R. Spliceosome Structure and Function. Cold Spring Harb Perspect in Biol. 2011; 3: 1-23.

29. Corsini L, Bonnal S, Basquin J, Hothorn M, Scheffzek K, Valcarcel J, and Sattler M. U2AF-homology motif interactions are required for alternative splicing regulation by SPF45. Nat Struct Mol Biol. 2007; 14: 620-9.

30. Liu Y, Conaway L, Rutherford Bethard J, Al-Ayoubi AM, Thompson Bradley, A, Zheng H, Weed SA, and Eblen ST. Phosphorylation of the alternative mRNA splicing factor 45 (SPF45) by Clk1 regulates its splice site utilization, cell migration and invasion. Nucleic Acids Res. 2013; 41: 494962.

31. Krystal GW, Armstrong BC, and Battey JF. N-myc mRNA forms an RNA-RNA duplex with endogenous anti-sense transcripts. Mol Cell Biol. 1990; 10: 4180-91.

32. Munroe SH and Lazar MA. Inhibition of c-erbA mRNA splicing by a naturally occuring antisense RNA. J Biol Chem. 1991; 266: 22083-6.

33. Hastings ML, Ingle HA, Lazar MA, and Munroe SH. Posttranscriptional regulation of thyroid hormone receptor expression by cis-acting sequences and a naturally occuring antisense RNA. J Biol Chem. 2000; 275: 11507-13.

34. Beltran M, Puig I, Pena C, Garcia JM, Alvarez AB, Pena $\mathrm{R}$, Bonilla $\mathrm{F}$, and de Herreros AG. A natural antisense transcript regulates Zeb2/Sip1 gene expression during Snail1-induced epithelial-mesenchymal transition. Genes Dev. 2008; 22: 756-69.

35. Jolly C and Lakhotia SC. Human sat III and Drosophila hsr omega transcripts: a common paradigm for regulation of nuclear RNA processing in stressed cells. Nucleic Acids Res. 2006; 34: 5508-14.

36. Johnsson P, Ackley A, Vidarsdottir L, Lui WO, Corcoran M, Grandér D, and Morris KV. A pseudogene longnoncoding-RNA network regulates PTEN transcription and translation in human cells. Nat Struct Mol Biol. 2013; 20:440-6.

37. Graveley BR. Alternative splicing: increasing diversity in the proteomic world. Trends Genet. 2001; 17: 100-7. doi: 10.1016/S0168-9525(00)02176-4

38. Cascino I, Papoff G, Eramo A, and Ruberti G. Soluble Fas/ Apo-1 splicing variants and apoptosis. Front Biosci. 1996; 1: d12-8.

39. Cheng J, Zhou T, Changdan L, Shapiro JP, Brauer MJ, Kiefer MC, Barr PJ, and Mountz JD. Protection from Fasmediated apoptosis by a soluble form of the Fas molecule. Science. 1994; 263: 1759-62.

40. Lu KH, Li W, Liu XH, Sun M, Zhang M1, Wu WQ, Xie WP, and Hou YY. Long non-coding RNA MEG3 inhibits NSCLC cells proliferation and induces apoptosis by affecting p53 expression. BMC Cancer. 2013; 13: 461.

41. Pickard MR, Mourtada-Maarabouni M, and Williams GT. Long non-coding RNA GAS5 regulates apoptosis in prostate cancer cell lines. Biochim Biophys Acta. 2013; 1832: 1613-23.

42. Zou Y, Jiang Z, Yu X, Sun M, Zhang Y, Zuo Q, Zhou J, Yang N, Han P, Ge Z, De W, and Sun L. Upregulation of Long Noncoding RNA SPRY4-IT1 modulates proliferation, migration, apoptosis, and network formation in trophoblast cells HTR-8SV/neo. PLoS One. 2013; 8: e79598.

43. Wu W, Zhang S, Li X, Xue M, Cao S, and Chen W. 2013. Ets-2 regulates cell apoptosis via the Akt pathway, through the regulation of urothelial cancer associated 1, a long noncoding RNA, in bladder cancer cells. PLoS One. 2013; 8: e73920.

44. Schwerk C and Schulze-Osthoff K. Regulation of apoptosis by alternative pre-mRNA splicing. Mol Cell. 2005; 19: $1-13$.

45. Izquierdo JM, Majos N, Bonnal S, Martinez C, Castelo R, Guigo R, Bilbao D, and Valcarcel J. Regulation of Fas alternative splicing by antagonistic effects of TIA-1 and 
PTB on exon definition. Mol Cell. 2005; 19:475-84.

46. Sampath J, Long PR, Shepard RL, Xia X, Devanarayan V, Sandusky GE, Perry 3rd WL, Dantzig AH, Williamson M, Rolfe M, and Moore RE. Human SPF45, a splicing factor, has limited expression in normal tissues, is overexpressed in many tumors, and can confer a multidrug-resistant phenotype to cells. Am J Pathol. 2003; 163: 1781-90.

47. Al-Ayoubi AM, Zheng H, Liu Y, Bai T, and Eblen ST. Mitogen-activatred protein kinase phosphorylation of splicing factor 45 (SPF45) regulates SPF45 alterantive splicing site utilization, proliferation and cell adhesion. Mol Cell Biol. 2012; 32: 2880-93.

48. De Maria R, Testa U, Luchetti L, Zeuner A, Stassi G, Pelosi E, Riccioni R, Felli N, Samoggia P, and Peschle C. Apoptotic role of Fas/Fas ligand system in the regulation of erythropoiesis. Blood. 1999; 93: 796-803.

49. Singer GG and Abbas AK. The fas antigen is involved in peripheral but not thymic deletion of $\mathrm{T}$ lymphocytes in $\mathrm{T}$ cell receptor transgenic mice. Immunity. 1994; 1: 365-71.

50. Inaba H, Komada Y, Li QS, Zhang XL, Tanaka S, Azuma E, Yamamoto H, and Sakurai M. mRNA expression of variant Fas molecules in acute leukemia cells. Am J Hematol. 1999; 62:150-8.

51. Liu JH, Wei S, Lamy T, Li Y, Epling-Burnette PK, Djeu JY, and Loughran TP, Jr. Blockade of Fas-dependent apoptosis by soluble Fas in LGL leukemia. Blood. 2002; 100: 1449-53.

52. Martin DA, Zheng L, Siegel RM, Huang B, Fisher GH, Wang J, Jackson CE, Puck JM, Dale J, Straus SE, Peter ME, Krammer PH, Fesik S, and Lenardo MJ. Defective CD95/APO-1/Fas signal complex formation in the human autoimmune lymphoproliferative syndrome, type 1a. Proc Natl Acad Sci USA. 1999; 96: 4552-57.

53. Tsai MC, Manor O, Wan Y, Mosammaparast N, Wang JK, Lan F, Shi Y, Segal E, and Chang HY. Long noncoding RNA as modular scaffold of histone modification complexes. Science. 2010; 329: 689-93.

54. Wilber A, Tschulena U, Hargrove PW, Kim YS, Persons DA, Barbas CF, and Nienhuis AW. A zinc-finger transcriptional activator designed to interact with the beta-globin gene promoters enhances fetal hemoglobin production in primary human adult erythroblasts. Blood. 2010; 115: 3033-41. 